\title{
Taxon-specific or universal? Using target capture to study the evolutionary history of rapid radiations
}

Gil Yardeni ${ }^{1, *}$, Juan Viruel ${ }^{2}$, Margot Paris $^{3}$, Jaqueline Hess $^{1,4}$, Clara Groot Crego ${ }^{1,5}$, Marylaure de La Harpe ${ }^{1}$, Norma Rivera ${ }^{1}$, Michael H. J. Barfuss ${ }^{1}$, Walter Till ${ }^{1}$, Valeria Guzmán-Jacob $^{6}$, Thorsten Krömer ${ }^{7}$, Christian Lexer ${ }^{1, * *}$, Ovidiu Paun ${ }^{1, * *}$, and Thibault $\operatorname{Leroy}^{1, * *}$

${ }^{1}$ Department of Botany and Biodiversity Research, University of Vienna, Rennweg 14, A-1030 Vienna, Austria

${ }^{2}$ Royal Botanic Gardens, Kew, Richmond, Surrey, TW9 3DS United Kingdom

${ }^{3}$ Department of Biology, Unit of Ecology 8 Evolution, University of Fribourg, Fribourg, Switzerland

${ }^{4}$ Department of Soil Ecology, Helmholtz Centre for Environmental Research, UFZ, Halle (Saale), Germany

${ }^{5}$ Vienna Graduate School of Population Genetics, Vienna, Austria

${ }^{6}$ Biodiversity, Macroecology and Biogeography, University of Goettingen, Göttingen, Germany

${ }^{7}$ Centro de Investigaciones Tropicales, Universidad Veracruzana, José María Morelos 44-46, Xalapa, Veracruz, Mexico

* corresponding author: gil.c.yardeni@gmail.com

** shared last authorship 


\section{Taxon-specific or universal?}

$1 \quad$ Abstract - Target capture has emerged as an important tool for phylogenetics and 2 population genetics in non-model taxa. Whereas developing taxon-specific capture probes 3 requires sustained efforts, available universal kits may have a lower power to reconstruct 4 relationships at shallow phylogenetic scales and within rapidly radiating clades. We present

5 here a newly-developed target capture set for Bromeliaceae, a large and ecologically-diverse 6 plant family with highly variable diversification rates. The set targets 1,776 coding regions, 7 including genes putatively involved in key innovations, with the aim to empower testing of a 8 wide range of evolutionary hypotheses. We compare the relative power of this taxon-specific 9 set, Bromeliad1776, to the universal Angiosperms353 kit. The taxon-specific set results in

higher enrichment success across the entire family, however, the overall performance of both kits to reconstruct phylogenetic trees is relatively comparable, highlighting the vast potential of universal kits for resolving evolutionary relationships. For more detailed phylogenetic or population genetic analyses, e.g. the exploration of gene tree concordance, nucleotide diversity or population structure, the taxon-specific capture set presents clear benefits. We discuss the potential lessons that this comparative study provides for future phylogenetic and population genetic investigations, in particular for the study of evolutionary radiations.

Keywords - target capture, plant radiation, Bromeliaceae, Tillandsia, population structure, phylogenomics

\section{Introduction}

Targeted sequencing approaches have emerged as a promising tool for studying evolutionary relationships in non-model taxa, enabling researchers to retrieve large data sets while requiring few genomic resources (Bossert \& Danforth, 2018; Escudero, Nieto-Feliner, Pokorny, Spalink, \& Viruel, 2020; McDonnell et al., 2021; Soto-Gomez et al., 2019). Using custom baits, the method largely retrieves the same loci across a wide taxonomic scale, obtains comparable and mergeable data sets, and may be combined with genome-skimming (E. M. Lemmon \& Lemmon, 2013; Weitemier et al., 


\section{Taxon-specific or universal?}

2014). Pre-existing knowledge of the targeted loci further provides opportunities to address specific questions on both deep and shallow timescales (Hale, Gardner, Viruel, Pokorny, \& Johnson, 2020; A. R. Lemmon, Emme, \& Lemmon, 2012). Finally, the method does not necessarily require a reference genome, is highly cost-effective, and with the ability to sequence herbarium samples, reduces the need for extensive sampling campaigns (Blaimer, Lloyd, Guillory, \& Brady 2016; Hale et al. 2020; Weitemier et al., 2014). Target capture has been successfully applied to resolve phylogenies in diverse groups, from arthropods such as bees (Xylocopa, Blaimer et al., 2016; Apidae, Bossert et al., 2019) and Araneae (Hexathelidae, Hedin, Derkarabetian, Ramírez, Vink, \& Bond, 2018) to mammals (Cetacea, McGowen et al., 2020), and in numerous plant groups (Heuchera, Folk, Mandel, \& Freudenstein, 2015; Gesneriaceae, Ogutcen et al., 2021; Zingiberales, Sass, Iles, Barrett, Smith, \& Specht, 2016 to name a few). The method's utility for studies at micro-evolutionary scales has been to date marginally explored, but several studies have pointed to the ability to analyze genomic diversity and estimate population genomic parameters (Choquet et al., 2019; Christmas, Biffin, Breed, \& Lowe, 2017; de La Harpe et al., 2019; Derrien \& Ramos-Onsins, 2020; Sanderson, DiFazio, Cronk, Ma, \& Olson, 2020). Nonetheless, the development of probes for target enrichment may pose several challenges: first, the need to identify regions conserved enough to ensure recovery, yet polymorphic enough to provide ample information (Soto-Gomez et al., 2019; Villaverde et al., 2018). Second, probe design requires detecting regions without pervasive copy number polymorphism (Kadlec, Bellstedt, Maitre, \& Pirie, 2017; A. R. Lemmon et al., 2012), a particular challenge for angiosperms and other groups, where duplication events are ubiquitous (Van de Peer, Mizrachi, \& Marchal, 2017).

In contrast, universal kits offer an attractive alternative that require reduced efforts to establish, and provide comparable data sets across wider ranges of taxa (Johnson et al., 2019; Kadlec et al., 2017). Such kits were designed to retrieve single-copy markers, for example, in the broad scope of amphibians (Hime et al., 2021), anthozoans (Quattrini et al., 2018), vertebrates (A. R. Lemmon et al., 2012) or angiosperms (Johnson et al., 2019). In the latter example, the Angiosperms353 kit is designed to target 353 single-copy genes across angiosperms. So far the kit has been employed successfully in resolving phylogenies, including but not limited to Nepenthes (Murphy et al., 2020), 


\section{Taxon-specific or universal?}

Schefflera (Shee, Frodin, Cámara-Leret, \& Pokorny, 2020) and the rapid radiations of Burmeistera (Bagley, Uribe-Convers, Carlsen, \& Muchhala, 2020) and Veronica (Thomas et al., 2021), establishing the kit as an eminent tool in macroevolutionary research. Its utility at microevolutionary levels is yet to be fully realized, although several works have established its suitability to deliver informative signals at a lower taxonomic level (Beck et al., 2021) and in acquiring population genomics parameters (Slimp, Williams, Hale, \& Johnson, 2021). The use of highly-conserved markers in a universal kit may, however, limit resolution power. Generally, taxon-specific baits are expected to deliver a higher information content and hence more accurate results (Kadlec et al., 2017), as enrichment success is known to drop with the level of divergence between sequences used for probe design and the targeted taxa (Liu et al., 2019). However, one study comparing the power of the universal Angiosperms353 kit and a taxon-specific kit to resolve phylogenomic relationship in Cyperaceae reported surprisingly similar performance (Larridon et al., 2020) and similar findings were reported in Malinae (Ufimov et al., 2021) and in Ochnaceae (Shah et al., 2021). It remains to be established whether these findings apply to other taxa and other evolutionary scales, including at population level, where ample genomic variability is required to resolve intra-specific relationships and investigate patterns of genetic differentiation.

Until recently, the technology available to investigate evolutionary questions in rapidly evolving groups featuring high net diversification rates has presented major obstacles, in particular for non-model groups. Decreasing costs of sequencing coupled with an ever-growing plethora of bioinformatic tools for data processing and downstream analysis has led to an increase in the use of methods like whole-genome sequencing, RNA sequencing and restriction site associated DNA sequencing (RAD-Seq) in lieu of traditional methods employing few conserved markers (de La Harpe et al., 2017; McKain, Johnson, Uribe-Convers, Eaton, \& Yang, 2018; Weitemier et al., 2014; Zimmer \& Wen, 2013). Whole-genome sequencing however remains costly, posing barriers for research targeting large numbers of samples, organisms with large genomes and non-model organisms, for which the availability of high-quality genomic resources is often limited (Hollingsworth, Li, van der Bank, \& Twyford, 2016; Supple \& Shapiro, 2018). While RAD-seq is an affordable alternative and widely used in population genetics, the resulting data sets may fall short when screened for homologous 


\section{Taxon-specific or universal?}

83

sequences across distantly related lineages (but see e.g., Heckenhauer, Samuel, Ashton, Abu Salim, \& Paun, 2018). Additionally, RAD-seq is less feasible when using degraded DNA from herbarium samples, and the use of short and inconsistently-represented loci across phylogenetic sampling may result in low information content and difficulties in assessing paralogy (E. M. Lemmon \& Lemmon, 2013; McKain et al., 2018; Jones \& Good, 2016).

Rapid evolutionary radiations are key stages in the evolutionary history across the Tree of Life and highly recurrent, hence an essential part of biodiversity research (Gavrilets \& Losos, 2009; Givnish et al., 2014; Hughes, Nyffeler, \& Linder, 2015; Soltis, Folk, \& Soltis, 2019; Soltis \& Soltis, 2004). Fast evolving groups provide potent opportunities to investigate important questions in evolutionary biology, such as the interplay between ecological and evolutionary processes in shaping biodiversity. A few notable study systems are the cichlid fish (McGee et al., 2020; Salzburger, 2018), Heliconius butterflies (Dasmahapatra et al., 2012; Moest et al., 2020), Anolis lizards (McGlothlin et al., 2018; Stroud \& Losos, 2020), Darwin's finches (Lamichhaney et al., 2015; Zink \& VázquezMiranda, 2019), white-eyes birds (Moyle, Filardi, Smith, \& Diamond, 2009) and New World lupins (Nevado, Atchison, Hughes, \& Filatov, 2016). Nevertheless, much remains unknown about the genomic basis underlying species diversification outside these intensively studied systems.

Research of rapidly diversifying lineages presents several challenges. First, a brief diversification period typically leads to imperfect reproductive barriers and incomplete lineage sorting, reflected in significant gene tree discordance and ambiguous relationships (Degnan \& Rosenberg, 2009; Lamichhaney et al., 2015; Pease, Haak, Hahn, \& Moyle, 2016; Straub et al., 2014). In addition, understanding 'speciation through time' poses a methodological challenge, and requires connecting two conceptual worlds: macroevolutionary investigations, concerned with spatial and ecological patterns over deeper timescales, and microevolutionary approaches, providing insight into the processes acting during population divergence and speciation (Bragg, Potter, Bi, \& Moritz, 2016; de La Harpe et al., 2017). Resolving phylogenomic relationships and disentangling the contribution of different genomic processes through time typically requires large-scale genomic datasets and thorough taxon sampling efforts (E. M. Lemmon \& Lemmon, 2013; Linder, 2008; Straub et al., 2012).

Here, we present Bromeliad1776, a new bait set for targeted sequencing, designed to address 


\section{Taxon-specific or universal?}

111 a wide range of evolutionary hypotheses in Bromeliaceae: from producing robust phylogenies to

studying the interplay of genomic processes during speciation and the genetic basis of trait shifts, such as photosynthetic and pollination syndrome. This highly diverse Neotropical radiation provides an excellent research system for studying the drivers and constraints of rapid adaptive radiation (Benzing, 2000; Givnish et al., 2011; Loiseau et al., 2021; Mota et al., 2020; Palma-Silva \& Fay, 2020; Wöhrmann, Michalak, Zizka, \& Weising, 2020). Bromeliaceae as a whole is considered an adaptive radiation (Benzing, 2000; Givnish et al., 2011) and contains several rapidly radiating lineages, most notably within Bromelioideae (Aguirre-Santoro, Salinas, \& Michelangeli, 2020) and Tillandsioideae (Loiseau et al., 2021). It is a species-rich and charismatic monocot family, consisting of over 3,000 species, including crops in the genus Ananas and other economically important species (Luther, 2008). Members of the family are characterized by a distinctive leaf rosette that often impounds rainwater in central tanks (phytotelmata). A diversity of arthropods and other animal species and microbes reside in bromeliad tanks, in some cases even leading to protocarnivory and other forms of nutrient acquisition (Givnish, Burkhardt, Happel, \& Weintraub, 1984; C. Leroy, Carrias, Céréghino, \& Corbara, 2016). Bromeliads present a diversity of repeatedly evolving adaptive traits, which allowed them to occupy versatile habitats and ecological niches (Benzing, 2000). CAM photosynthesis, water-absorbing trichomes, formation of tank habit, extensive rates of epiphytism and a diversity of pollination syndromes are some of the adaptations correlated with high rates of diversification within the family (Benzing, 2000; Crayn, Winter, \& Smith, 2004; Givnish et al., 2014; Kessler, Abrahamczyk, \& Krömer, 2020; Quezada \& Gianoli, 2011).

To assess the utility of the Bromeliad1776 kit, we performed a comparison between our taxonspecific kit and the universal Angiosperms353 kit using several methods across different evolutionary time-scales. We present Bromeliad1776 in the light of methodological considerations on bait design, data handling, analyses and other practical considerations. 
Taxon-specific or universal?

\section{Materials and Methods}

\subsection{Custom bait design}

Whole-genome sequences and gene models from Ananas comosus v.3 (Ming et al., 2015) were used to design a bait set aiming to target i) single-copy protein coding genes distributed across the whole genome, ii) genes previously described as associated with key innovation traits in Bromeliaceae (see below), iii) markers previously used for phylogenomic inference in Bromeliaceae and iv) genes orthologous to those in the Angiosperms353 bait set. The 1776 selected genes are detailed in Supporting information Table S1.

Genes in subset $i$ were selected based on genetic diversity parameters calculated using wholegenome sequence and RNAseq data previously published by de La Harpe et al., (2020; data publicly available online at SRA Bioproject PRJNA649109) with the PopGenome R package v.2.1.6 (Pfeifer, Wittelsbürger, Ramos-Onsins, \& Lercher, 2014). Genomic regions were retained in this category if they shared at least $70 \%$ identity between A. comosus and T. sphaerocephala, and if they had nucleotide diversity $(\pi)$ values not exceeding the $90 \%$ quantile of the $(\pi)$ distribution across genes for four Tillandsia species (Tillandsia australis, Tillandsia fasciculata, Tillandsia floribunda and T. sphaerocephala; data and analysis performed by de La Harpe et al. (2020). We further excluded genes with a total exonic size smaller than $1,100 \mathrm{bp}$, or individual exons smaller than $120 \mathrm{bp}$. Next, copy-number variation was calculated based on clustering of A. comosus and Tillandsia transcriptome assemblies to generate three copy number categories - "single copy", "low copy" (i.e., less than five copies) and "high copy" (i.e., five or more copies). We included only single-copy genes in the design for bait subset $i$. Finally, we excluded genes that were located in genomic regions outside those assigned to linkage groups in the A. comosus reference (Ming et al., 2015). A total of 1,243 genes were identified for this part.

The bait subset of genes associated with key innovative traits in Bromeliaceae (subset ii above) included (1) genes putatively under positive selection along branches relevant to C3/CAM shifts (de La Harpe et al., 2020), (2) genes that exhibit differential gene expression between CAM 


\section{Taxon-specific or universal?}

and C3 Tillandsia species (de La Harpe et al., 2020) and (3) genes putatively associated with photosynthetic and developmental functions, or with flavonoid and anthocyanin biosynthesis, according to the literature (e.g. Ming et al., 2015; Palma-Silva, Ferro, Bacci, \& Turchetto-Zolet, 2016; Wai et al., 2017; Goolsby, Moore, Hancock, Vos, \& Edwards, 2018). Ananas comosus genes with the highest match scores (calculated as lowest E-score in BLASTP, Madden (2013) against the sequences of genes from the literature were added to the bait set (see Supporting information Table S2 for details). A total of 1,612 genes underpinning innovative traits were included in the bait design, regardless of criteria used for subset $i$ for size, similarity and duplication rate.

Markers previously used for phylogenomic inference in Bromeliaceae (subset iii) were obtained from the literature, spanning 13 genes (e.g. Barfuss et al., 2016; Machado et al., 2020; Schulte, Barfuss, \& Zizka, 2009, see TS2 for full list). Genes orthologous to those in the Angiosperms353 bait set (Johnson et al., 2019) were identified using the orthologous gene models from A. comosus based on gene annotations (Ming et al., 2015) or using BLASTP (Madden, 2013), totalling 281 genes.

Finally, we used a draft genome of $T$. fasciculata (Jaqueline Hess, personal communication) to exclude from all candidates genes that exhibited multiple BLASTN hits, if they have not been previously described as duplicated within the genus (de La Harpe et al., 2020). Specifically, we excluded genes that matched another genomic sequence of at least 100bp with high similarity score $(>80 \%)$ and low E-value $\left(<10^{-5}\right)$. In an additional round of filtering performed by the manufacturer of the final bait set, Arbor Biosciences (Ann Arbor, MI, USA), multi-copy genes with sequences that are more than $95 \%$ identical were collapsed into a single sequence and baits with more than $70 \%$ GC content or containing at least $25 \%$ repeated sequences were excluded. In addition, targets including exons smaller than $80 \mathrm{bp}$ were completed with regions flanking the exons according to the $A$. comosus reference genome. The final kit included 1776 genes: 801 genes in subset $i, 681$ genes associated with key innovative traits, 13 genes representing phylogenetic markers and 281 genes orthologous to the Angiosperms353 set. Probes were designed with 57,445 80-mer baits tiling across targets in $2 \mathrm{x}$ coverage, targeting approximately $2.3 \mathrm{Mbp}$. The kit is subsequently referred to as the Bromeliad1776 bait set. Further specifications can be found in Supporting information 
Taxon-specific or universal?

Tables S1 and S2 and in the github repository: https://github.com/giyany/Bromeliad1776/tree/ main/MS_2021_scripts.

\subsection{Plant material collection}

We sampled a total of 70/72 Bromeliaceae samples (for Angiosperms353 and for Bromeliad1776, accordingly; Supporting information Table S3), including 56 accessions from the Tillandsioideae subfamily and 16 representing the other subfamilies, except Navioideae. The divergence time between Tillandsioideae and subfamily Bromelioideae to which A. comosus belongs is estimated at $15 \mathrm{Mya}$ (according to Givnish et al. 2014). Within Tillandsioideae, we sampled 38/40 individuals from five species of the Tillandsia subgenus Tillandsia ('clade K' in Barfuss et al. (2016); Sampling in Mexican populations illustrated in Supporting information Figure S1).

\subsection{Library preparation \& enrichment}

DNA extractions were performed using a modified CTAB protocol (Doyle \& Doyle, 1987), purified using Nucleospin ${ }^{\circledR}$ gDNA cleanup kit from Macherey-Nagel (Hudlow et al., 2011) following the supplier's instructions with a two-fold elution step and finally quantified with Qubit ${ }^{\circledR} 3.0$ Fluorometer (Life Technologies, Ledeberg, Belgium).

For each sample, 200ng DNA was sheared using Bioruptor ${ }^{\circledR}$ Pico sonication device (Diagenode, Seraing, Belgium) aiming for an average insert size of $350 \mathrm{bp}$, dried in a speed vacuum Eppen-

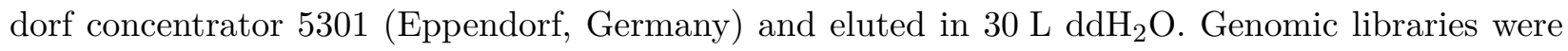
prepared using the NEBNext ${ }^{\circledR}$ Ultra TM II DNA Library Prep Kit for Illumina (New England Biolabs, Ipswich, MA, United States) using reagents at half volumes following Hale et al. (2020) and using 11 PCR cycles, increased up to 13 cycled for libraries with low genomic output. Samples were double-indexed with NEBNext ${ }^{\circledR}$ Multiplex Oligos for Illumina ${ }^{\circledR}$ (New England Biolabs,

Ipswich, MA, USA). Fragment sizes were inspected with Agilent Bioanalyzer (Agilent Technologies, Santa Clara, CA, USA) and concentrations were measured with Qubit $^{\circledR} 3.0$ Fluorometer. Subpools of 11-14 equimolar genomic libraries were prepared using phylogenetic proximity and DNA concen- 


\section{Taxon-specific or universal?}

trations of the genomic libraries, which ranged from 2.62 to $118.0 \mathrm{ng} / \mathrm{L}$, following Soto-Gomez et al. (2019).

We used the Angiosperms353 and the Bromeliad1776 bait sets from Arbor Biosciences (Ann Arbor, MI, USA) to enrich each subpool of genomic libraries independently with a single hybridization reaction of myBaits ${ }^{\circledR}$ target capture kits from Arbor Biosciences (Ann Arbor, MI, USA), following Hale et al. (2020). Average fragment size and DNA yield were estimated for each subpool using Agilent Bioanalyzer and Qubit ${ }^{\circledR}$ 3.0 Fluorometer. Subpools were then pooled in equimolar conditions and sequenced at Vienna BioCenter Core Facilities (Vienna, Austria) on Illumina ${ }^{\circledR}$ NextSeq $^{\text {TM }} 550$ (2x150bp, Illumina, San Diego, CA). Sequencing was conducted independently for either bait kit.

\subsection{Data processing}

The raw sequence data in BAM format was demultiplexed using deML v.1.1.3 (Renaud, Stenzel, Maricic, Wiebe, \& Kelso, 2015) and samtools view v.1.7 (Li et al., 2009), converted to fastq using bamtools v.2.4.0 (Barnett, Garrison, Quinlan, Strömberg, \& Marth, 2011) and quality checked using FastQC v.0.11.7 (Andrews, 2010). Reads were then trimmed for adapter content and quality using TrimGalore v.0.6.5 (Krueger, 2019), a wrapper tool around FastQC and Cutadapt, using settings -fastqc - retain unpaired. Sequence quality and adapter removal was confirmed with FastQC reports.

Quality and adapter-trimmed reads were aligned to A. comosus reference genome v.3 (Ming et al., 2015) using bowtie2 (Langmead \& Salzberg, 2012) with the -very-sensitive-local option to increase sensitivity and accuracy. Samtools (Li et al., 2009) was then used to remove low quality mapping and sort alignments by position, and PCR duplicates were marked using MarkDuplicates from PicardTools v.2.25 (Picard Toolkit, 2019). Summary statistics of the mapping step were generated using samtools stats. Variants were called using freebayes v1.3.2-dirty (Garrison \& Marth, 2012) and sites marked as MNP/complex were decomposed and normalized using the script 'vcfallelicprimitives' from vcflib (Garrison, 2012). Next, AN/AC field was calculated using bcftools v.1.7 (Li, 2011) and variant calls were filtered using vcflib (Garrison \& Marth, 2012) and 


\section{Taxon-specific or universal?}

bcftools. Given that freebayes does not perform automatic variant filtering steps, we identified sets of parameters that generate reliable final SNP sets, based on two independent criteria: the highest transition/transversion ratios as reported by SnpSift (SnpEff suite, Cingolani et al., 2012) and the lowest $\pi_{\mathrm{N}} / \pi_{\mathrm{S}}$ (see section 2.7 below). After a detailed evaluation, we used the following criteria to generate two high quality SNP sets, one for each bait-set: we considered genotype calls with per-sample coverage below $10 \times$ as missing (NA) and excluded variants (i) marked as indels or neighboring indels within a distance of $3 \mathrm{bp}$, (ii) with depth of coverage at the SNP level lower than $500 \times$, (iii) with less than ten reads supporting the alternate allele at the SNP level, or (iv) with more than $40 \%$ missing data. All genes in the Bromeliad1776 that passed the filtering criteria were included in the SNP set, regardless of their function. Summary statistics of the final SNP sets were generated using the script vcf2genocountsmatrix.py, namely the total number of SNPs, the proportion of on-target SNPs and the proportion of SNPs in some specific genomic contexts, with A. comosus genome v.3 as a reference. The full data processing script align_and_trim.sh and the vcf2genocountsmatrix.py script are both available at https://github.com/giyany/Bromeliad1776.

\subsection{Bait specificity and efficiency}

To explore bait specificity, we calculated the percentage of high quality trimmed reads ontarget using samtools stats and bedtools intersect v2.25.0 (Quinlan \& Hall, 2010) using the script calculat_bait_target_specifity.sh (available from https://github.com/giyany/Bromeliad1776). Targets for Bromeliad1776 were defined as the bait sequences plus their 500 bp flanking regions. Targets for Angiosperms353 were defined using orthogroups to A. comosus: gene annotations from the bait set were used to assign genes to orthogroups using OrthoFinder (Emms \& Kelly, 2019). When several orthogroups were found for a single Angiosperms353 gene, we included all, resulting in 559 A. comosus genes assigned to orthogroups. Within the orthgroups, targets were again defined as exonic regions plus their 500 bp flanking regions.

To provide insights into determinants of bait capture success, we calculated bait efficiency for all baits of Bromeliad1776. For each bait, efficiency was calculated as the number of high-quality reads uniquely mapping to each bait target region, averaged over samples. We then tested for the 


\section{Taxon-specific or universal?}

correlation of capture efficiency to several bait characteristics (copy number, GC content, number and size of exons in targeted gene, size of baits and phylogenetic distance to A. comosus) with a generalized linear model or Kruskal-Wallis test in R v.4.0.3 (R Core Team, 2020) using a negative binomial family.

\subsection{Phylogenomic analyses}

We inferred phylogenomic relationships for all samples using two methods: a concatenation method, and a coalescent-based species tree estimation. The latter method was included as concatenation methods do not account for gene tree incongruence, which may result in high support for an incorrect topology (Kubatko \& Degnan, 2007), especially in the presence of notable incomplete lineage sorting. In addition, gene tree incongruence analysis provides insight into molecular genome evolution, including the extent of incomplete lineage sorting and other genomic processes such as hybridization and introgression (Galtier \& Daubin, 2008; Wendel \& Doyle, 1998).

We used the the variant and non-variant genotypes to create a phylip matrix with vcf2phylip v.2.0 (Ortiz, 2019) and constructed a maximum-likelihood species tree for each bait set with RAxML-NG v.0.9.0 (Kozlov, Darriba, Flouri, Morel, \& Stamatakis, 2019), using 250 bootstrap replicates and a GTR model with an automatic MRE-based bootstrap convergence test. Next, we constructed a species tree using ASTRAL-III v.5.7.7 (hereafter: ASTRAL, Zhang, Rabiee, Sayyari, \& Mirarab, 2018). For both the Angiosperms353 and the Bromeliad1776 sets, we separated the matrix into independent genomic windows, defining each window as a gene according to the known exons and a 500bp flanking region. For Angiosperms353, we extracted the 559 genes (assigned to orthogroups as explained above) as genomic windows using bedtools intersect. For Bromeliad1776, genomic windows were extracted using the A. comosus gene sequences included in bait design. All loci and all accessions were included in species tree inference regardless of the percentage of missing data, since taxon completeness of individual gene trees is important for statistical consistency of this approach, and we expected only low levels of fragmentary sequences (Mirarab, 2019; Nute, Chou, Molloy, \& Warnow, 2018). After excluding genes with zero coverage, 269 genes and 1,600 genes were included in species tree inference for Angiosperms353 and Bromeliad1776, respectively. 


\section{Taxon-specific or universal?}

For each gene, a maximum-likelihood gene tree was inferred using ParGenes (Morel, Kozlov, \& Stamatakis, 2019) with RAxML-NG (Kozlov et al., 2019), using a GTR model with an automatic MRE-based bootstrap convergence test. Loci with insufficient signal may reduce the accuracy of species tree estimation (Mirarab, 2019), hence, in all gene trees, nodes with a bootstrap support smaller than ten were collapsed using Newick utilities (Junier \& Zdobnov, 2010). A species tree was then generated in ASTRAL with quartet support and posterior probability for each tree topology. The number of conflicting gene trees was calculated using phyparts and visualized using the script phypartspiecharts.py (available from https://github.com/mossmatters/MJPythonNotebooks).

\subsection{Population structure and nucleotide diversity estimates}

To explore the genetic structure within the Tillandsia species complex, we focused on five species from 15 localities (Supporting information Table S3 and Supporting information Figure S1). We first used plink v.1.9 (Chang et al., 2015) to filter out SNPs in linkage disequilibrium. Population structure was further explored through individual ancestry analysis, with identity-bydescent matrix calculated by plink and inference of population structure using ADMIXTURE v.1.3. with $\mathrm{K}$ values ranging from one to ten, and 30 replicates for each $\mathrm{K}$, using a block optimization method (Alexander \& Lange, 2011). A summary of the ADMIXTURE results was obtained and presented using pong (Behr, Liu, Liu-Fang, Nakka, \& Ramachandran, 2016). The set of LD-pruned biallelic SNPs was further filtered to allow a maximum of $10 \%$ missing data and used to perform a principal components analysis (PCA) with SNPRelate v.1.20.1 (Zheng et al., 2012). Finally, for each Tillandsia species, we used the strategy of T. Leroy et al. (2021) to compute synonymous $\left(\pi_{\mathrm{S}}\right)$ and non-synonymous $\left(\pi_{\mathrm{N}}\right)$ nucleotide diversities and Tajima's D, from fasta sequences using seq_stat_coding (T. Leroy et al., 2021). 
Taxon-specific or universal?

\section{Results}

\subsection{Higher mapping rates and capture efficiency for taxon-specific set}

On average, 4,401,958 (803,464-12,693,516) paired-end reads per accession were generated per Angiosperms353 library and 2,962,023 (1,282,762-6,298,880) per Bromeliad1776 library. Overall, the mapping rates to the $A$. comosus reference genome were higher for libraries enriched with Bromeliad1776, with an average mapping rate of $82.3 \%$ (61.8\%-95.9\%) and $42.8 \%(22.1 \%-77.9 \%)$, for Bromeliad1776 and Angiosperms353, respectively (Supporting information Figure S2, Supporting information Table S4). Higher mapping rates were recorded for subfamilies Bromelioideae and Puyoideae, as compared to Tillandsioideae, for both the Angiosperms353 and Bromeliad1776 sets (see Supporting information Figures S3 and S4, respectively). This may reflect the effect of reference bias, and in the case of Bromeliad1776, it may be further amplified by our kit design based on $A$. comosus (subfamily Bromelioideae). Bait specificity was high for Bromeliad1776 with on average 90.4\% reads on-target (76.5\%-94.2\%), while for Angiosperms353 bait specificity was 14.0\% (4.6\%30.1\%; see Supporting information Figure S2). Mapping rates and bait specificity were positively correlated for both bait sets (GLM, P<0.01).

\subsection{Bait efficiency depends on the genomic context}

We investigated factors that may influence bait efficiency, starting with the contribution of gene copy number variation. We assumed three categories regarding the number of paralogs per orthogroup: single copy, low-copy (i.e., less than five copies) and high-copy (i.e., five or more copies). The number of gene copies had a significant effect on bait efficiency and post-hoc Dunn's test supported significant differences in efficiency for comparisons between low-copy and high-copy, and between single-copy and low-copy $\left(\mathrm{P}=2.8^{-44}\right)$. Low-copy genes exhibit the lowest enrichment success, suggesting that the bait efficiency is not simply correlated to the number of gene copies (Figure 1). We also recovered a significant effect of the intragenic GC content and GC content of the baits on bait efficiency (GLM, $\left.\mathrm{P}=1.5^{-68}\right)$. Finally, we investigated the possible link between 
Taxon-specific or universal?

342

efficiency and gene structure. Average exon sizes $\left(\mathrm{P}<2.0^{-16}\right)$ and total number of exons per gene $\left(\mathrm{P}=1.1^{-89}\right)$ were also positively correlated with enrichment success. The size of the smallest exon for all targeted genes was however not correlated with bait efficiency. Sequence similarity, measured as percent of identity between Tillandsia sequences and those of $A$. comosus, was positively correlated with capture success $\left(\mathrm{P}=4.8^{-13}\right.$; Figure 1$)$.
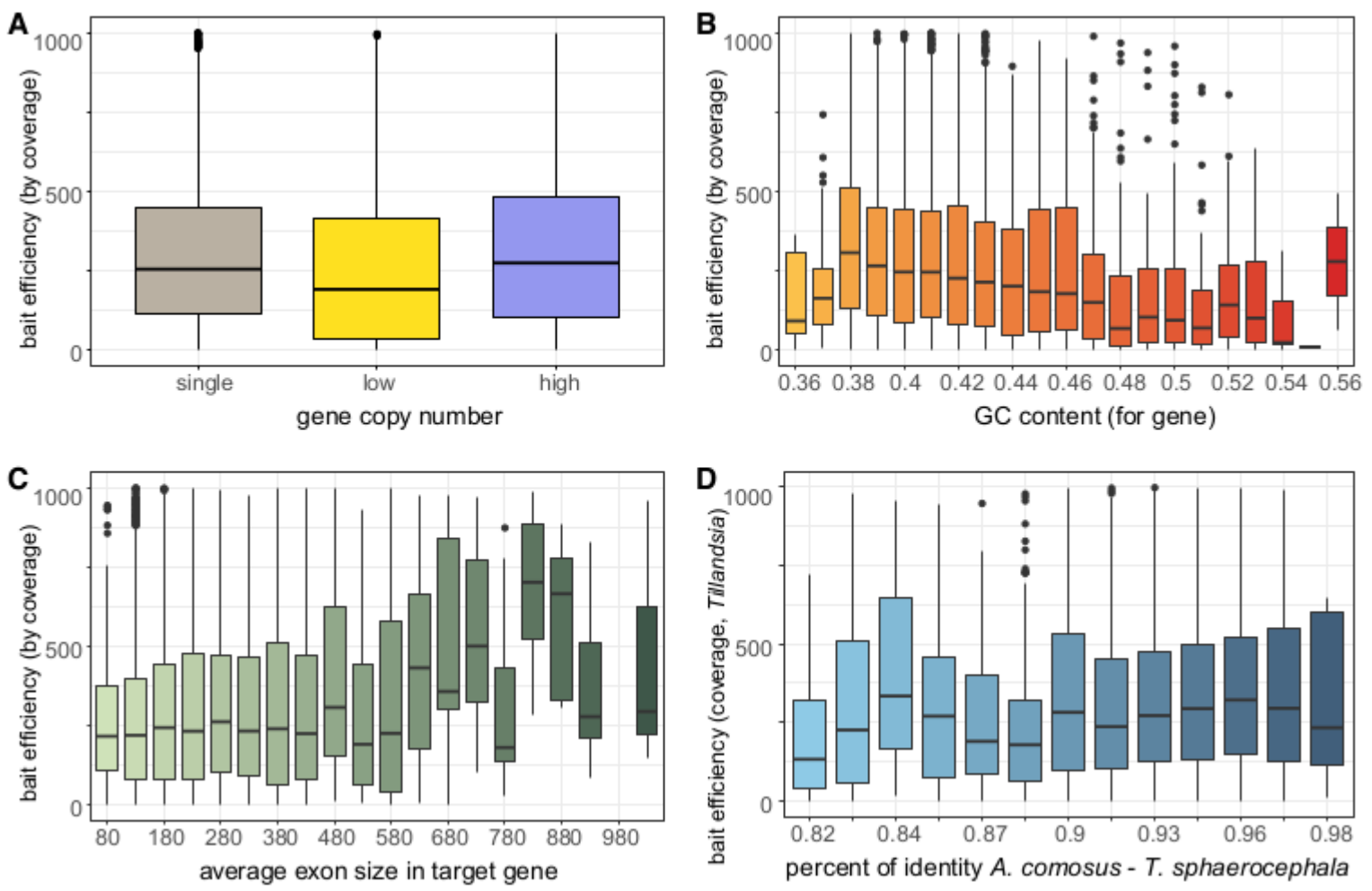

Figure 1 Effects of (A) putative gene copy number, (B) gene $G C$ content, $(C)$ average exon size, and (D) percent of identity on bait efficiency in Bromeliad1776 bait set, measured as the number of high-quality reads uniquely mapping to bait target region across samples. Continuous variable was binned and y-values higher than 1,000 excluded for visualization in B-D.

\subsection{Both kits provided a large number of SNPs}

After variant calling and filtering, we identified 47,390 and 209,186 high-quality SNPs for the Angiosperms353 and the Bromeliad1776 bait sets, respectively. On average, missing data represented $23.7 \%$ of genotype calls per individual in Angiosperms 353 , but only $6.3 \%$ for the 


\section{Taxon-specific or universal?}

Bromeliad1776 kit. The differences in amount of missing data are likely associated with the higher mean depth per site across the Bromeliad1776 kit $(6,602)$, as compared to Angiosperms353 $(3,437)$. Focusing on the subgenus Tillandsia, we identified 15,622 SNPs for Angiosperms353 (including a total of $18.9 \%$ missing data) compared to 65,473 polymorphic sites $(2.9 \%$ missing data) for Bromeliad1776. In both full data sets and the subset including only Tillandsia samples, Bromeliad1776 recovered more variants in intronic regions compared with Angiosperms353. Angiosperms353 recovered a large proportion of off-target SNPs, whereas in Bromeliad1776 approximately $15 \%$ of the SNPs were recovered from flanking regions (Table 1). We discuss ascertainment bias that may rise due to the non-random selection of markers in the supporting information.

\subsection{Similar phylogenomic resolution in concatenation method, Bromeliad1776 outperforms Angiosperms353 for species tree reconstruction}

The Angiosperms353 and Bromeliad1776-based maximum-likelihood phylogenetic trees recovered the same backbone phylogeny of Bromeliaceae, clustering subfamily Tillandsiaoedeae and the subgenus Tillandsia with high bootstrap values (Supporting information Figure S5). Neither set obtained high support for inter-population structure for Tillandsia gymnobotrya, but highlysupported nodes separated T. fasciculata accessions from Mexico and from other locations, and the populations of $T$. punctulata for the Bromeliad1776 data set were similarly separated. The tree topologies were identical, with the notable exception of the placements of Tillandsia biflora and Racinaea ropalocarpa and the genus Deuterocohnia (Supporting information Figure S5, purple arrow). Overall, internal nodes are strongly supported for both sets, except for Hechtia carlsoniae as sister to Tillandsioideae, which is poorly supported for both sets. While several internal nodes are slightly less supported for the Angiosperms353 set, overall these results demonstrate the efficacy of both kits in phylogenomic reconstruction using concatenation approaches, indicating that as few as 47k SNPs within variable regions provide reliable information to resolve phylogenetic relationships within the recent evolutionary radiation of Tillandsia.

Species trees as inferred with ASTRAL for both data sets likewise provided an overall strong local posterior support (Figure 2, see also Supporting information). Several nodes however exhibit 


\section{Taxon-specific or universal?}

lower local posterior support values for the Angiosperms353 tree than for the Bromeliad1776 tree. The topology for the Bromeliad1776 ASTRAL tree was similar to the ML tree, but differed again by placing Deuterocohnia as sister taxa to Puyoideae only. In the Angiosperms353 tree, the topology differed from both ML trees and the ASTRAL Bromeliad1776 tree in several nodes. H. carlsoniae was placed as a sister taxa to all other subfamilies in the Angiosperm353 phylogeny. Notably, the placement of Catopsis and Glomeropitcrania differed, as well as the placement of Cipurosis subandinai, T. biflora and $R$. ropalocarpa. Several internal nodes were poorly supported, such as the node separating the tribe Catopsideae and core Tillandsioideae, and the nodes separating Tillandsioideae from all other subfamilies. The differences in topology between the Angiosperms353 ASTRAL tree to all other trees (ML trees and Bromeliad1776 ASTRAL tree) together with the low posterior support suggest lower resolution power and a poor fit of this data set for resolving a species tree.

The length and average size of the input gene trees different among sets, with average window length of $304.6 \mathrm{bp}$ and $819.9 \mathrm{bp}$ and average gene tree support of 16.9 and 38.9 for Angiosperms353 and Bromeliad1776 bait-sets, respectively (Figure 2). An examination of gene tree concordance constructed with Bromeliad1776 data set allowed us to identify variable levels of gene tree conflict among nodes (Figure 2). Gene tree discordance was especially high for the split between Tillandsioideae and other subfamilies, as well as for the split between Puyoideae and taxa assigned to Bromelioideae. Furthermore, gene tree discordance and the proportion of un-informative gene trees was especially high for splits among clades within the K.1 and K.2 clades of subgenus Tillandsia. A similar analysis with Angiosperms353 yielded evidence for gene tree discordance, but a considerable number of gene trees were reported to be non-informative (grey part of the pie charts), especially within subgenus Tillandsia (Figure 2). 
bioRxiv preprint doi: https://doi.org/10.1101/2021.05.20.444989; this version posted September 20, 2021. The copyright holder for this preprint (which was not certified by peer review) is the author/funder, who has granted bioRxiv a license to display the preprint in perpetuity. It is made available under aCC-BY-NC 4.0 International license.

Taxon-specific or universal?

Bromeliad1776
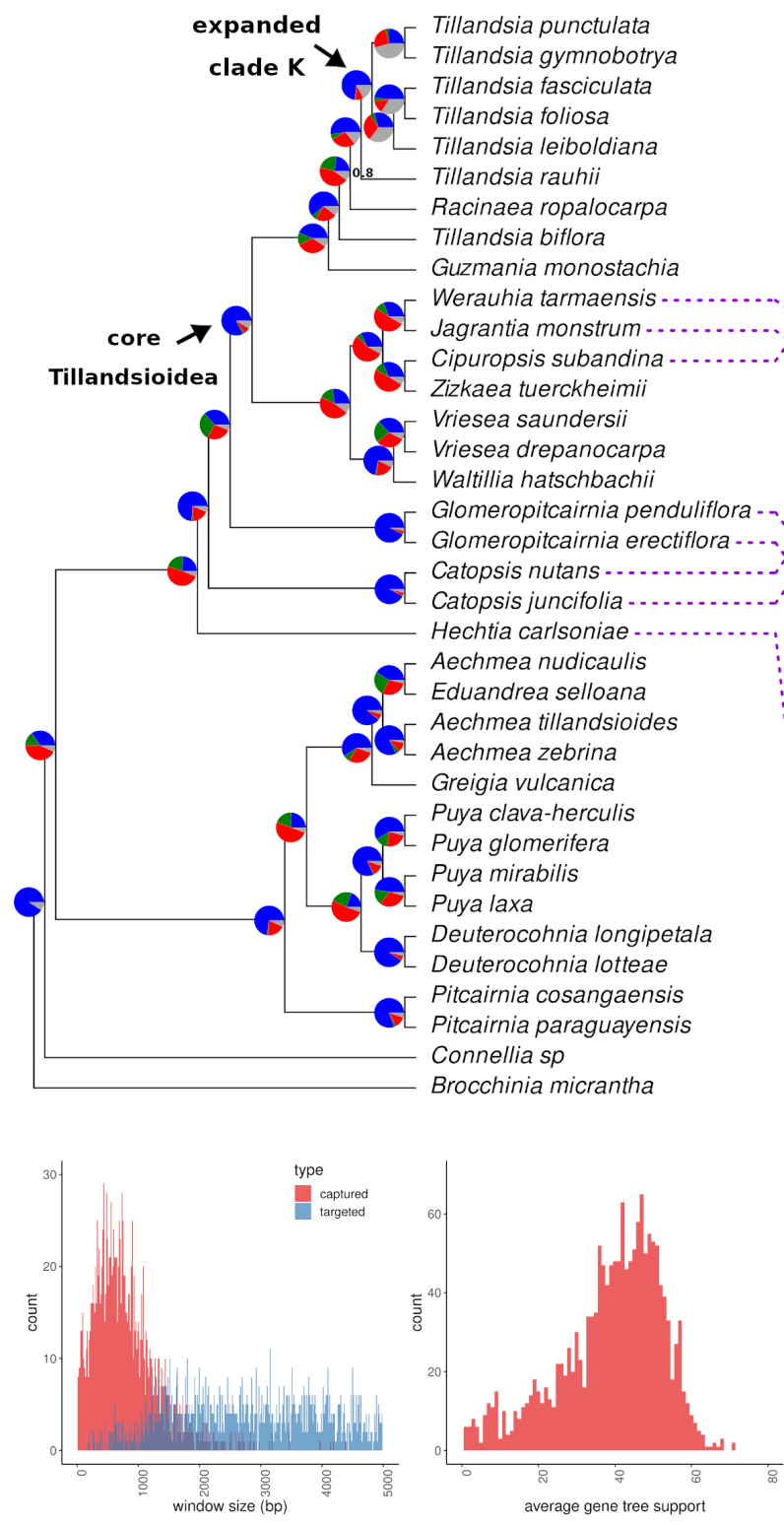
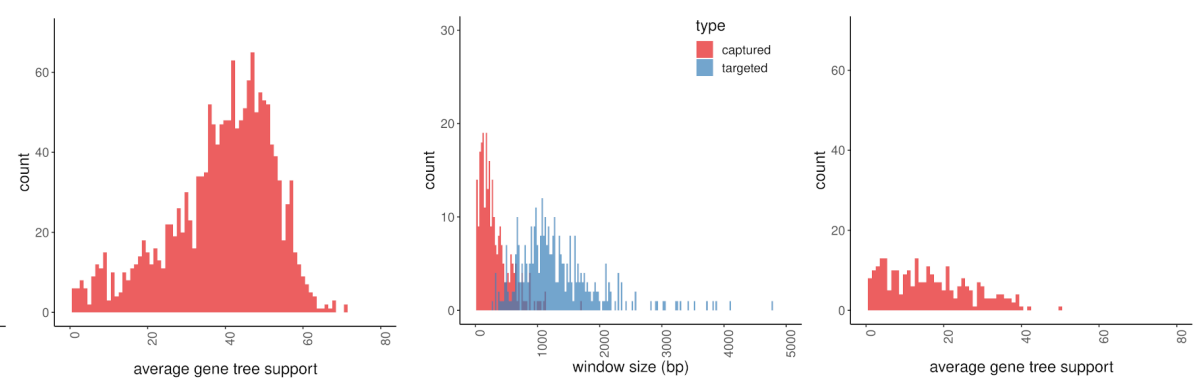

406

Figure 2 Coalescent-based species trees generated ASTRAL-III for samples enriched with Bromeliad1776 (left) and Angiosperms353 (right, flipped for mirroring), on 269 and 1600 genes for each set, respectively. Node values represent local posterior probabilities (pp) for the main topology and are equal to 1 unless noted otherwise. Pie charts at the nodes show levels of gene tree discordance: the percentages of concordant gene trees (blue), the top alternative bipartition (green), other conflicting topologies (red) and uninformative gene trees (gray). At bottom, length and average bootstrap support for gene trees from either data set, according to the design of the bait set used for enrichment: 
Taxon-specific or universal?

414

415

Angiosperms353 (right) and Bromeliad1776 (left). Each gene was considered a single genomic window.

\subsection{Strong interspecific structure, but little evidence for within-species popula- tion structure}

After LD-pruning and retaining maximum 10\% missing data, 1,025 and 32,941 biallelic SNPs were included for the Tillandsia PCA analysis of the Angiosperms353 and Bromeliad1776 data sets, respectively. Overall, both data sets provided evidence for interspecific structure, but not for population structure, with Bromeliad1776 resulting in border-line higher resolution (slightly better separating $T$. foliosa from $T$. fasciculata). The percentage of explained variance was higher in the Bromeliad1776 set (19.3\% and $16.5 \%$ for PC1 and PC2) as compared to the Angiosperms353 data set (14.5\% and 11.8\%, see Figure 3, Supporting information Figure S6). Based on these two PCAs, we found no evidence for spatial genetic structure within each species, since accessions did not cluster by geographic origin on the two PCs presented, or any other PCs we investigated (See

Supporting information Figure S6). 
bioRxiv preprint doi: https://doi.org/10.1101/2021.05.20.444989; this version posted September 20, 2021. The copyright holder for this preprint (which was not certified by peer review) is the author/funder, who has granted bioRxiv a license to display the preprint in perpetuity. It is made available under aCC-BY-NC 4.0 International license.

Taxon-specific or universal?
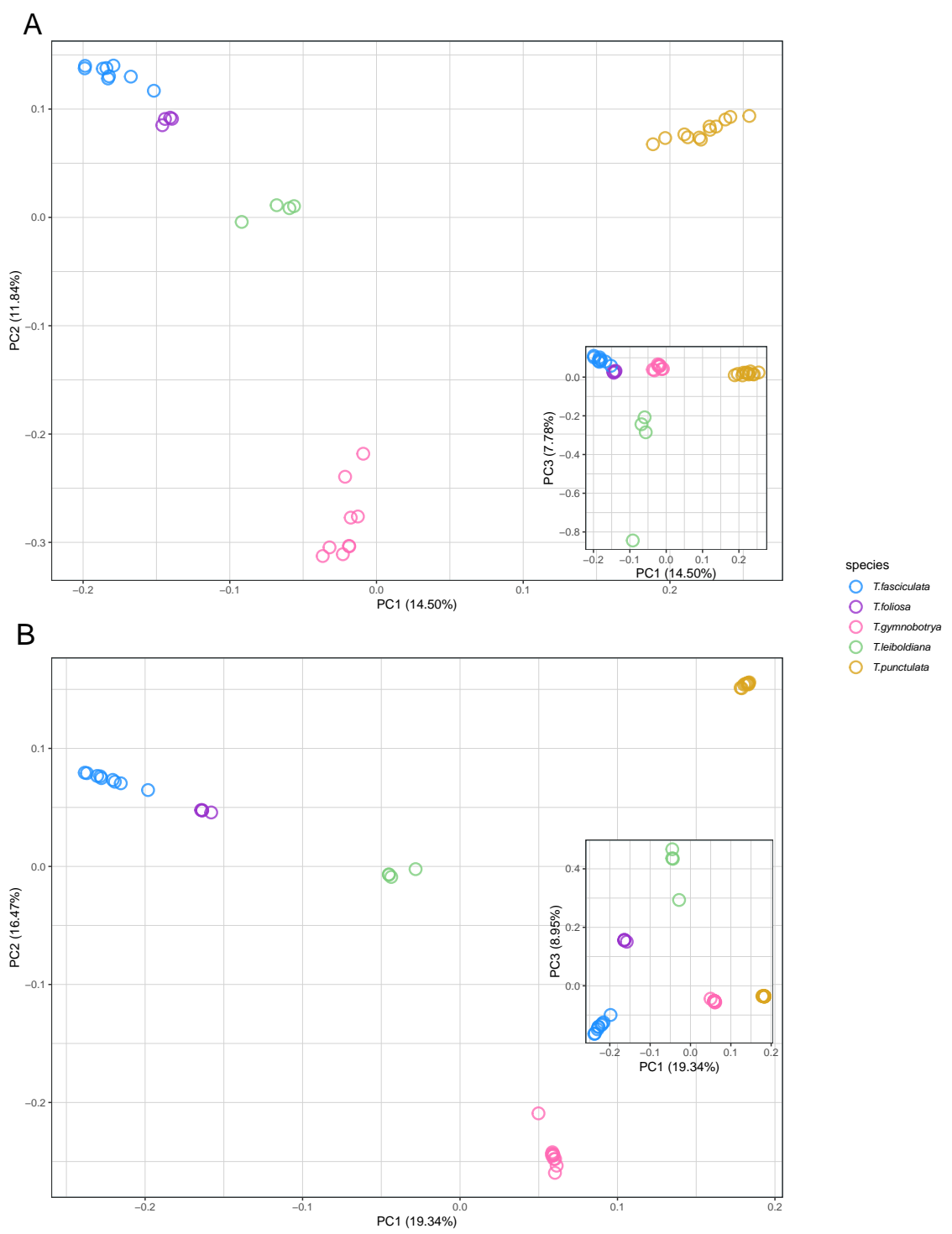

Figure 3 Principal Component Analysis (PCA) plot for samples of Tillandsia subgenus Tilland-

432

433

sia enriched with two bait sets: A. Angiosperms353 (1,025 variants); B. Bromeliad1776 (32,941 variants). Colors indicate different species according to legend.

In addition to PCA, we performed ADMIXTURE analyses based on 9,804 and 42,613 variants for the Angiosperms353 and Bromeliad1776 sets, respectively (Figure 4). We used a cross-validation strategy to identify the best $\mathrm{K}$ and found clear support for $\mathrm{K}=5$ for the Bromeliad1776 set (Sup- 
Taxon-specific or universal?

porting information Figure S7). In contrast, the CV pattern for the Angiosperms353 set varied widely, providing limited information about the best K. Lowest CV values were however observed for $\mathrm{K}=9$ with locally low values for $\mathrm{K}=5$ and $\mathrm{K}=3$ (Supporting information Figure $\mathrm{S} 7$ ). We further investigated the ADMIXTURE bar plots at different values of $\mathrm{K}$. For $\mathrm{K}=5$, very similar patterns can be observed for both sets, with the recovered clusters reflecting the expected species boundaries. The main difference between the two data sets was the ability of the Bromeliad1776 set to reach a more consistent solution ("consensus") among 30 runs, especially at large K, as compared to the runs based on the Angiosperms353 bait set. The Bromeliad1776 was also able to distinguish between different sampling localities of $T$. punctulata and of T. fasciculata at K=7-8 (Figure 4).

\section{Bromeliad1776}

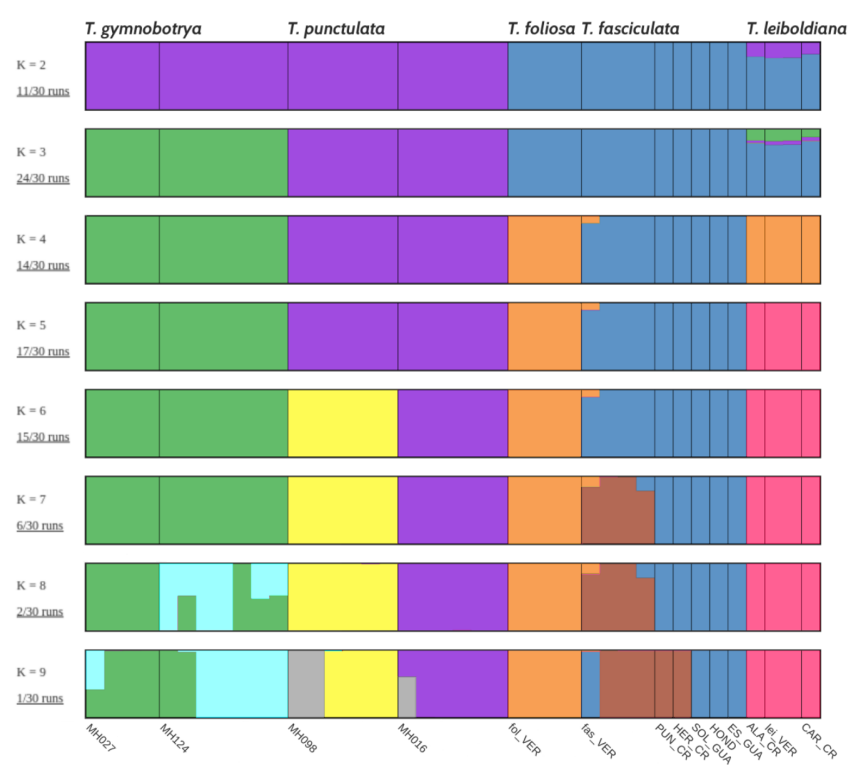

\section{Angiosperms353}

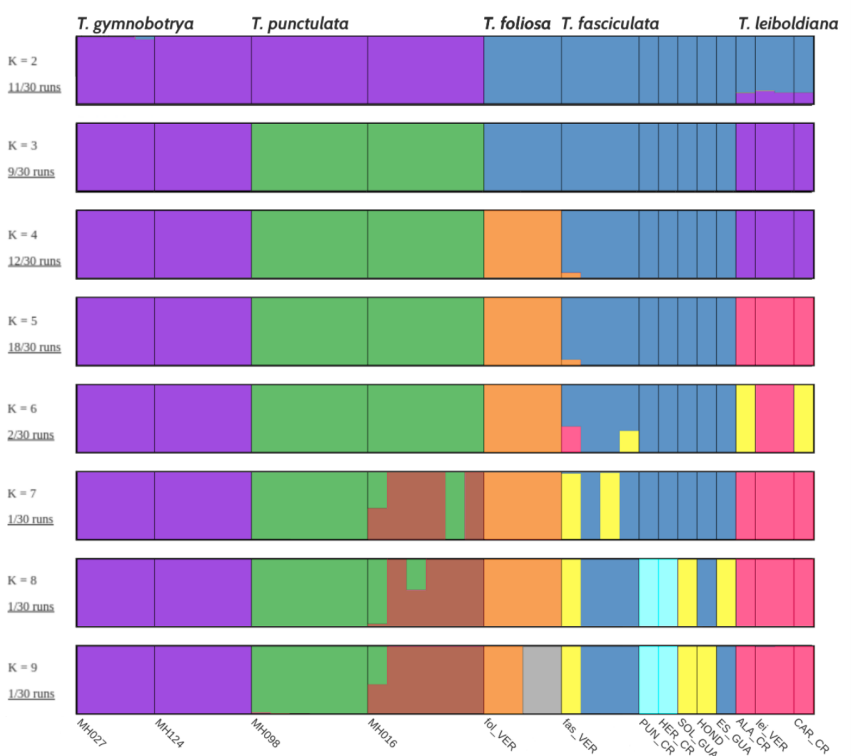

Figure 4 Population structure of 5 Tillandsia subgenus Tillandsia species from 14 sampling locations inferred with the ADMIXTURE software. Samples were enriched with either of two bait sets: Angiosperms353 (9,804 variants after LD-pruning) and Bromeliad1776 (42,613 variants after LD-pruning), showing values of $K=2$ to $K=9$. Colors represent genetically differentiated groups while each accession is represented by a vertical bar. 
Taxon-specific or universal?

\subsection{Distinct diversities hint at different demographic processes}

Nucleotide diversity estimates were calculated for the Bromeliad1776 data-set only, due to difficulties obtaining a reliable SNP set with Angiosperms353 (see section 2.4). Averaged levels of nucleotide diversity at synonymous sites $\pi_{\mathrm{S}}$ greatly varied among species, from $4.1 \times 10^{-3}$ to $8.1 \times 10^{-3}$ for T. foliosa and T. fasciculata, respectively (Supporting information Table S5; Figure 5). Given the recent divergence of these different species and their roughly similar life history traits, they are expected to share relatively similar mutation rates, hence the observed differences in $\pi_{\mathrm{S}}$ are expected to translate into differences of long-term $\mathrm{N}_{\mathrm{e}}$. Looking at the distribution of $\pi_{\mathrm{S}}$ across genes, we foundbroader or narrower distributions depending on the species, which explains the observed differences in averaged $\pi_{\mathrm{S}}$, as typically represented by the median of the distribution (vertical bars, Figure 5). Most species exhibit distributions of Tajima's D (Fig 5) that are centered around zero, with the notable exception of T. punctulata. The distribution of this species is shifted toward positive Tajima's D values, therefore indicating a recent population contraction, suggesting that this species experienced a unique demographic trajectory as compared to the other species.
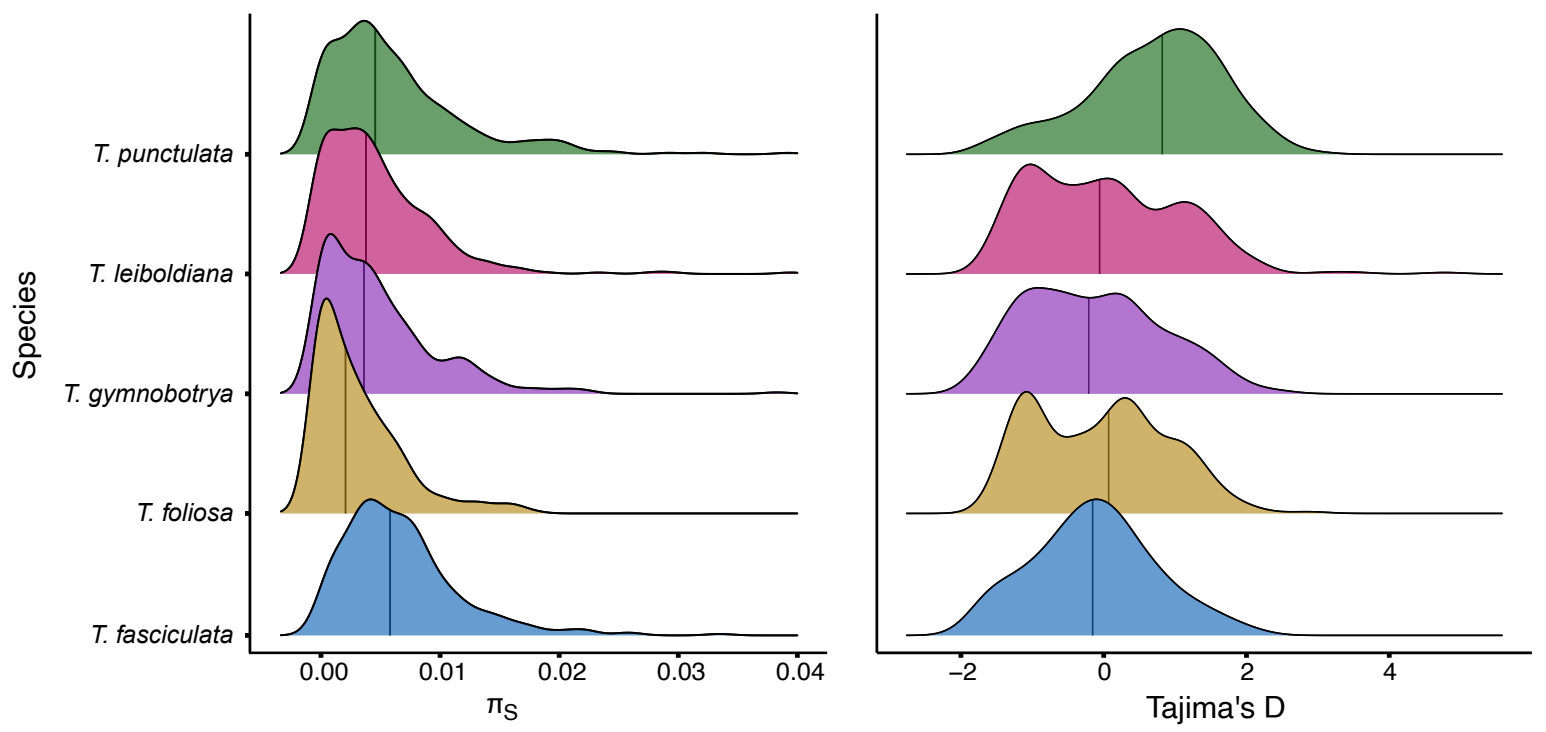

Figure 5 Distribution of Tajima's $D$ and synonymous $\left(\pi_{S}\right)$ nucleotide diversity within each species for the Bromeliad1776 kit. 
Taxon-specific or universal?

\section{Discussion}

\subsection{A taxon-specific bait set performs marginally better for phylogenomics}

In this study, we compared the information content and performance of a taxon-specific bait set and a universal bait set for addressing questions on evolutionary processes at different scales in a highly diverse Neotropical plant group, including recently radiated clades. We found that the taxon-specific kit provided a greater number of segregating sites, yet contrary to our expectations, the abundance of information content did directly translate to a greater resolution power.

The universal and taxon-specific sets performed comparably when investigating macroevolutionary patterns: the inferred species trees are remarkably consistent between the two bait sets (Supporting information Figure S5, Figure 2). Notably, both sets were sufficiently informative to reconstruct the relationships among the fastest radiating clades. These results resonate with previous comparative works (e.g. in Burmeistera, Bagley et al., 2020; in Buddleja, Chau, Rahfeldt, \& Olmstead, 2018; and in Cyperus, Larridon et al., 2020), where taxon-specific markers provided higher gene assembly success, but a comparable number of segregating sites for phylogenetic inference, indicating that universal bait sets are nearly as effective as taxon-specific bait sets, even in fast evolving taxa. The main advantage of the bromeliad taxon-specific set is its ability to provide additional resolution for deeper examination of gene tree incongruence (Figure 2), currently a fundamental tool in phylogenomic research (Edwards, 2009; Morales-Briones et al., 2020; Pease et al., 2016).

The taxon-specific bait set performed marginally better to address hypotheses at more recent evolutionary scales and provided arguably clearer evidence for inference of species genomic structure using clustering methods. In fact, genetic markers obtained from both data sets provided sufficient information to infer species but no geographic structure, suggesting that Tillandsia could be characterized by high gene dispersal among populations. Considering that the Angiosperms353 kit has shown potential to provide within-species signal, as recently demonstrated by Beck et al. (2021) on Solidago ulmifolia, and to estimate demographic parameters from herbarium specimen (Slimp et al., 


\section{Taxon-specific or universal?}

2021), we would expect the taxon-specific set to accurately reveal a geographical genetic structure. However, the present study is generally based on small sample sizes per species $(n=4-8)$, mostly sampled within a limited geographic range, limiting our ability to draw robust conclusions on the levels of intra-specific population structure.

The Bromeliad1776 kit provided a substantially larger number of segregating sites (more than 200k vs. 47k in Angiosperms353; Table 1, Supporting information Figure S2) due to higher enrichment success, following the expectation for higher sequence variation in custom-made loci (Figure 1, see also Bragg et al., 2016; de La Harpe et al., 2019; Kadlec et al., 2017). We accordingly found that rates of molecular divergence are distinctly correlated with enrichment success in our sampling (Figure 1), following the expectation that a universal kit will provide fewer segregating sites.

However, the difference in resolution power between the kits cannot be ascribed solely to the different numbers of SNPs, but rather to the length and variability of the obtained regions. The topology obtained with the Angiosperm353 data set under the multi-species coalescent model was substantially different from all other inferred trees and the input gene trees provided a low power to detect patterns of gene tree discordance (Figure 2). We additionally observed that the highly conserved regions targeted by Angiosperms353 are shorter in comparison to Bromeliad1776 targets and thus result in shorter input windows for species tree inference (Figure 2). Hence, the patterns of gene tree discordance in the Angiosperms353 data set likely indicate incorrect gene tree estimation or other model misspecifications, rather than a biological signal. Specifically, coalescence-based methods are sensitive to gene tree estimation error (Zhang et al., 2018) and perform better with gene trees estimated from unlinked loci long enough and variable enough to render sufficient signal per gene tree - this is especially true for data sets with many taxa. The high rates of uninformative genes trees, found in almost half of the intergenic nodes in the Angiosperms353 data set, is expected with increased levels of gene tree error which in turn reduce the accuracy of ASTRAL (Mirarab, 2019; Sayyari \& Mirarab, 2016). In contrast, the Bromeliad1776 ASTRAL tree (Figure 2, left) resolved phylogenetic relationships among taxa with high posterior probability and a topology similar to the ML tree. Gene tree discordance analysis revealed high incongruence around certain nodes, possibly 


\section{Taxon-specific or universal?}

reflecting rapid speciation events.

Since inference of phylogenetic relationships under the multi-species coalescent and exploration of gene tree discordance are both pivotal to phylogenomic research (Degnan \& Rosenberg, 2009; Edwards et al., 2016; Pease et al., 2016), a taxon-specific kit provides a clear advantage especially in recent rapid radiations, where gene tree conflict and incomplete lineage sorting are expected to be prevalent (Dornburg, Su, \& Townsend, 2019; Kubatko \& Degnan, 2007; Roch \& Warnow, 2015). In that regard, inference of the species tree with the Bromeliad1776 is a tool to drive further hypotheses concerning evolutionary and demographic processes in the evolution of Tillandsia. Moreover, the features of the loci targeted provide an important opportunity to study selection (see section 4.3).

\subsection{Insights on Bromeliaceae phylogeny and demographic processes in Tilland- sia}

Both bait sets resolved the phylogeny of Bromeliaceae, including the fastest evolving lineages of the subfamily Tillandsioideae. The results generally agreed with previous findings of the relationships among taxa (Givnish et al., 2011, 2014). Several findings that contrast with the expected known phylogeny may point at a complexity of genomic processes in the evolutionary history of Bromeliaceae subfamilies. Both the ML tree and species tree did not support a monophyly of the subfamily Pitcairnioideae, which was represented by four samples and two genera in our phylogeny: Deuterochonia and Pitcarnia. Rather, the genus Deuterochonia was sister to subfamily Puyoideae or sister to both Puyoideae and Bromelioideae subfamilies, inconsistent with the results of Barfuss et al. (2016) and Granados Mendoza et al. (2017). Interestingly, in a visualization of gene tree discordance we found high levels of incongruence and a high percentage of trees supporting an alternative topology in the node splitting the genera, indicating that several genomic processes such as hybridization and incomplete lineage sorting may have accompanied divergence in this group, contributing to the phylogenetic conflict and extending the challenges in resolving these evolutionary relationships. Within the core Tillandsioideae, the tribes Tillandsieae and Vrieseeae were found to be monophyletic, in accordance with previous work on the subfamily (Barfuss et al., 2016). Fi- 


\section{Taxon-specific or universal?}

nally, within our focal group Tillandsia subgenus Tillandsia, clade K as suggested by Barfuss et al. (2016) and clades K.1 and K.2 as proposed by Granados Mendoza et al. (2017) were all well supported, further in agreement with their interpretation of Mexico and Central America as a center of diversity for subgenus Tillandsia. Within Tillandsia, incongruence was prominent at the recent splits within clade K.1. and clade K.2 as expected in a recent rapid radiation, a result of high levels of incomplete lineage sorting, hybridization and introgression (Berner \& Salzburger, 2015).

When applied to methods in population genetics, we obtained some evidence for a difference in demographic processes and in the level of genetic variation among species. This was especially true for the taxon-specific bait set: for example, the bait set differentiated between populations of T. punctulata and T. fasciculata, but not T. gymnobotrya in a maximum likelihood tree and ancestry analysis (Supporting information Figure S5, Figure 4), indicating differences in inter-population genetic structure among species. The evidence for different demographic processes in these species extended to estimates of Tajima's D, where lower values may indicate a recent bottleneck. In addition, we found a unique distribution of nucleotide diversity for T. foliosa, possibly reflecting a low effective population size for this endemic species in contrast with the closely related, but widespread T. fasciculata. In all cases, our limited sampling given the large size of the family constrains our ability to draw conclusions of a 'true' phylogeny and to account for population structure. Our finding however suggests that nuclear markers obtained with a target capture technique can highlight genomic processes and be further applied to address questions in population genomics with a wider sampling scheme.

\subsection{Future prospects and implications for research in Bromeliaceae and rapid radiations}

Beyond the scope of this study, the availability of a bait set kit for Bromeliaceae provides a prime genetic resource for investigating several topical research questions on the origin and maintenance of Bromeliaceae diversity. Manyfold studies of bromeliad phylogenomics set forth the challenges of resolving species-level phylogenies with a small number of markers, particularly in young and speciose groups (Goetze, Zanella, Palma-Silva, Büttow, \& Bered, 2017; Granados Mendoza 


\section{Taxon-specific or universal?}

et al., 2017; Loiseau et al., 2021; Versieux et al., 2012 ). This particularly curated bait set allows highly efficient sequencing across taxa: within our study, we found high mapping success with $82.3 \%$ average read mapping. As expected, we documented a difference in enrichment success among taxa, explained by divergence time to the reference used for bait design (see Supporting information Figure S4), suggesting possible deviations from the assumptions of non-randomly distributed missing data that may mislead phylogenetic inference (A. R. Lemmon, Brown, Stanger-Hall, \& Lemmon, 2009; Streicher, Schulte, \& Wiens, 2016; Xi, Liu, \& Davis, 2016). However, given the large enrichment success, downstream analysis with deliberate methodology can account for possible biases and provide robust inference with strict data filtering (Molloy \& Warnow, 2018; Streicher et al., 2016). Hence, target enrichment with Bromeliad1776 can produce large data sets with consistent representation between taxa, allowing repeatability between studies and retaining the possibility for global synthesis by including sequence baits orthologous to the universal Angiosperms353 bait set. Moreover, with specific knowledge of the loci targeted in this set, the ability to obtain the same sequences across taxa and experiments and to differentiate genic regions with the use of $A$. comosus models, this bait set offers a broad utility for research in population genomics.

Another important feature in the Bromeliad1776 set is the inclusion of genes putatively associated with key innovative traits in Bromeliaceae with a focus on C3/CAM shifts. Little is known about the molecular basis of the CAM pathway, an adaptation to arid environments which evolved independently and repeatedly in over 36 plant families (Heyduk, Moreno-Villena, Gilman, Christin, \& Edwards, 2019; Chen, Xin, Wai, Liu, \& Ming, 2020; Silvera et al., 2010). CAM phenotypes are considered key adaptations in Bromeliaceae, associated with expansion into novel ecological niches. In Tillandsia, C3/CAM shifts were found to be particularly associated with increased rates of diversification (Crayn et al., 2004; de La Harpe et al., 2020; Givnish et al., 2014). The Bromeliad1776 bait set offers opportunities to address specific questions on the relationship between rapid diversification and photosynthetic syndromes in this clade, including testing for gene sequence evolution. Additionally, the inclusion of multi-copy genes, combined with newly developed pipelines for studying gene duplication and ploidy (Morales-Briones et al., 2020; Viruel et al., 2019), are beneficial for studying the role of gene duplication and loss in driving diversification. With the increasing 


\section{Taxon-specific or universal?}

ubiquity of target baits as a genomic tool we expect to see additional pipelines and applications emerging, further expanding the utility of target capture for both macro-and microevolutionary research.

\section{Conclusions}

Even as whole genome sequencing becomes increasingly economically feasible, target capture is expected to remain popular due to its extensive applications in research. We found that evaluating the differences in resolution power between universal and taxon-specific bait sets is far from a trivial task, and we attempted to lay out a methodological roadmap for researchers wishing to reconstruct the complex evolutionary history of rapidly diversifying lineages. While a taxon-specific set offers exciting opportunities beyond phylogenomic and into research of molecular evolution, its development is highly time-consuming, requires community-based knowledge and may cost months of work when compared with out-of-the-box universal kits. Our results suggest that universal kits can continue to be employed when aiming to reconstruct phylogenies, in particular as this may offer the possibility to use previously published data to generate larger data sets. However, for those wishing to deeply investigate evolutionary questions in certain lineages, a taxon-specific kit offers certain benefits during data processing stages, where knowledge of the design scheme and gene models is extremely useful, and the possible return of costs is especially high for taxa emerging as model groups. We furthermore encourage groups designing taxon-specific kits to include also universal probes, furthering the mission to complete the tree of life.

\section{Acknowledgments}

This paper is dedicated to Christian Lexer, a wonderful mentor, friend and colleague. The research was supported with funding from the Christian Lexer professorship startup BE772002. The analyses benefited from the Vienna Scientific Cluster (VSC) and the Montpellier Bioinformatics Biodiversity (MBB) platform services. We thank Huiying Shang and Aram Drevekenin for help 
Taxon-specific or universal?

with code, Kelly Swarts, Claus Vogl and Matt Johnson for insightful discussions and advice. We thank the members of Swiss SNSF Sinergia project CRSII3_147630 for accession sampling and three anonymous reviewers for their comments on an earlier version of this manuscript.

\section{References}

Aguirre-Santoro, J., Salinas, N. R., \& Michelangeli, F. A. (2020). The influence of floral variation and geographic disjunction on the evolutionary dynamics of Ronnbergia and Wittmackia (Bromeliaceae: Bromelioideae). Botanical Journal of the Linnean Society, 192(4), 609-624. doi: 10.1093/botlinnean/boz087

Alexander, D. H., \& Lange, K. (2011). Enhancements to the ADMIXTURE algorithm for individual ancestry estimation. BMC Bioinformatics, 12(1), 246. doi: 10.1186/1471-2105 $-12-246$

Andrews, S. (2010). FastQC: A quality control tool for high throughput sequence data. Babraham Bioinformatics, Babraham Institute, Cambridge, United Kingdom.

Bagley, J. C., Uribe-Convers, S., Carlsen, M. M., \& Muchhala, N. (2020). Utility of targeted sequence capture for phylogenomics in rapid, recent angiosperm radiations: Neotropical Burmeistera bellflowers as a case study. Molecular Phylogenetics and Evolution, 152, 106769. doi: 10.1016/j.ympev.2020.106769

Barfuss, M. H. J., Till, W., Leme, E. M. C., Pinzón, J. P., Manzanares, J. M., Halbritter, H., ... Brown, G. K. (2016). Taxonomic revision of Bromeliaceae subfam. Tillandsioideae based on a multi-locus DNA sequence phylogeny and morphology. Phytotaxa, 279(1), 1-97. doi: 10.11646/phytotaxa.279.1.1

Barnett, D. W., Garrison, E. K., Quinlan, A. R., Strömberg, M. P., \& Marth, G. T. (2011). BamTools: A C++ API and toolkit for analyzing and managing BAM files. Bioinformatics, 27(12), 1691-1692. doi: 10.1093/bioinformatics/btr174

Beck, J. B., Markley, M. L., Zielke, M. G., Thomas, J. R., Hale, H. J., Williams, L. D., \& Johnson, M. G. (2021). Is Palmer's elm leaf goldenrod real? The Angiosperms353 kit provides within-species signal in Solidago ulmifolia s.l. bioRxiv. doi: 10.1101/2021.01.07 .425781

Behr, A. A., Liu, K. Z., Liu-Fang, G., Nakka, P., \& Ramachandran, S. (2016). Pong: Fast analysis and visualization of latent clusters in population genetic data. Bioinformatics, 32(18), 2817-2823. doi: 10.1093/bioinformatics/btw327

Benzing, D. H. (2000). Bromeliaceae: Profile of an Adaptive Radiation. Cambridge University Press. 
Taxon-specific or universal?

Berner, D., \& Salzburger, W. (2015). The genomics of organismal diversification illuminated by adaptive radiations. Trends in Genetics, 31(9), 491-499. doi: 10.1016/j.tig.2015.07.002

Blaimer, B. B., Lloyd, M. W., Guillory, W. X., \& Brady, S. G. (2016). Sequence Capture and Phylogenetic Utility of Genomic Ultraconserved Elements Obtained from Pinned Insect Specimens. PLOS ONE, 11(8), e0161531. doi: 10.1371/journal.pone.0161531

Bossert, S., \& Danforth, B. N. (2018). On the universality of target-enrichment baits for phylogenomic research. Methods in Ecology and Evolution, 9(6), 1453-1460. doi: 10.1111/ 2041-210X.12988

Bossert, S., Murray, E. A., Almeida, E. A. B., Brady, S. G., Blaimer, B. B., \& Danforth, B. N. (2019). Combining transcriptomes and ultraconserved elements to illuminate the phylogeny of Apidae. Molecular Phylogenetics and Evolution, 130, 121-131. doi: 10.1016/ j.ympev.2018.10.012

Bragg, J. G., Potter, S., Bi, K., \& Moritz, C. (2016). Exon capture phylogenomics: Efficacy across scales of divergence. Molecular Ecology Resources, 16(5), 1059-1068. doi: 10.1111/ 1755-0998.12449

Chang, C. C., Chow, C. C., Tellier, L. C., Vattikuti, S., Purcell, S. M., \& Lee, J. J. (2015). Second-generation PLINK: Rising to the challenge of larger and richer datasets. GigaScience, 4(1). doi: 10.1186/s13742-015-0047-8

Chau, J. H., Rahfeldt, W. A., \& Olmstead, R. G. (2018). Comparison of taxon-specific versus general locus sets for targeted sequence capture in plant phylogenomics. Applications in Plant Sciences, 6(3), e1032. doi: 10.1002/aps3.1032

Chen, L.-Y., Xin, Y., Wai, C. M., Liu, J., \& Ming, R. (2020). The role of cis -elements in the evolution of crassulacean acid metabolism photosynthesis. Horticulture Research, 7(1), 1-8. doi: 10.1038/s41438-019-0229-0

Choquet, M., Smolina, I., Dhanasiri, A. K. S., Blanco-Bercial, L., Kopp, M., Jueterbock, A., ... Hoarau, G. (2019). Towards population genomics in non-model species with large genomes: A case study of the marine zooplankton Calanus finmarchicus. Royal Society Open Science, 6(2), 180608. doi: 10.1098/rsos.180608

Christmas, M. J., Biffin, E., Breed, M. F., \& Lowe, A. J. (2017). Targeted capture to assess neutral genomic variation in the narrow-leaf hopbush across a continental biodiversity refugium. Scientific Reports, 7(1), 41367. doi: 10.1038/srep41367

Cingolani, P., Platts, A., Wang, L. L., Coon, M., Nguyen, T., Wang, L., ... Ruden, D. M. (2012). A program for annotating and predicting the effects of single nucleotide polymorphisms, SnpEff. Fly, 6(2), 80-92. doi: 10.4161/fly.19695 
Taxon-specific or universal?

Crayn, D. M., Winter, K., \& Smith, J. A. C. (2004). Multiple origins of crassulacean acid metabolism and the epiphytic habit in the Neotropical family Bromeliaceae. Proceedings of the National Academy of Sciences, 101(10), 3703-3708. doi: 10.1073/pnas.0400366101

Dasmahapatra, K. K., Walters, J. R., Briscoe, A. D., Davey, J. W., Whibley, A., Nadeau, N. J., ... The Heliconius Genome Consortium (2012). Butterfly genome reveals promiscuous exchange of mimicry adaptations among species. Nature, 487(7405), 94-98. doi: 10.1038/ nature11041

de La Harpe, M., Hess, J., Loiseau, O., Salamin, N., Lexer, C., \& Paris, M. (2019). A dedicated target capture approach reveals variable genetic markers across micro- and macroevolutionary time scales in palms. Molecular Ecology Resources, 19(1), 221-234. doi: 10.1111/1755-0998.12945

de La Harpe, M., Paris, M., Hess, J., Barfuss, M. H. J., Serrano-Serrano, M. L., Ghatak, A., ... Lexer, C. (2020). Genomic footprints of repeated evolution of CAM photosynthesis in a Neotropical species radiation. Plant, Cell \& Environment, 43(12), 2987-3001. doi: $10.1111 /$ pce. 13847

de La Harpe, M., Paris, M., Karger, D. N., Rolland, J., Kessler, M., Salamin, N., \& Lexer, C. (2017). Molecular ecology studies of species radiations: Current research gaps, opportunities and challenges. Molecular Ecology, 26(10), 2608-2622. doi: 10.1111/mec.14110

Degnan, J. H., \& Rosenberg, N. A. (2009). Gene tree discordance, phylogenetic inference and the multispecies coalescent. Trends in Ecology 86 Evolution, 24(6), 332-340. doi: 10.1016/j.tree.2009.01.009

Derrien, T., \& Ramos-Onsins, S. (2020). Assessing a novel sequencing-based approach for population genomics in non-model species. Peer Community in Genomics, 1, 100002. doi: 10.24072/pci.genomics.100002

Dornburg, A., Su, Z., \& Townsend, J. P. (2019). Optimal Rates for Phylogenetic Inference and Experimental Design in the Era of Genome-Scale Data Sets. Systematic Biology, 68(1), 145-156. doi: 10.1093/sysbio/syy047

Doyle, J. J., \& Doyle, J. L. (1987). A rapid DNA isolation procedure for small quantities of fresh leaf tissue. PHYTOCHEMICAL BULLETIN, 19(1), 11-15.

Edwards, S. V. (2009). Is a New and General Theory of Molecular Systematics Emerging? Evolution, 63(1), 1-19. doi: 10.1111/j.1558-5646.2008.00549.x

Edwards, S. V., Xi, Z., Janke, A., Faircloth, B. C., McCormack, J. E., Glenn, T. C., ... Davis, C. C. (2016). Implementing and testing the multispecies coalescent model: A valuable paradigm for phylogenomics. Molecular Phylogenetics and Evolution, 94, 447-462. doi: 10.1016/j.ympev.2015.10.027 
Taxon-specific or universal?

Emms, D. M., \& Kelly, S. (2019). OrthoFinder: Phylogenetic orthology inference for comparative genomics. Genome Biology, 20(1), 238. doi: 10.1186/s13059-019-1832-y

Escudero, M., Nieto-Feliner, G., Pokorny, L., Spalink, D., \& Viruel, J. (2020). Editorial: Phylogenomic Approaches to Deal With Particularly Challenging Plant Lineages. Frontiers in Plant Science, 11. doi: 10.3389/fpls.2020.591762

Folk, R. A., Mandel, J. R., \& Freudenstein, J. V. (2015). A protocol for targeted enrichment of intron-containing sequence markers for recent radiations: A phylogenomic example from Heuchera (Saxifragaceae). Applications in Plant Sciences, 3(8), 1500039. doi: 10.3732/ apps. 1500039

Galtier, N., \& Daubin, V. (2008). Dealing with incongruence in phylogenomic analyses. Philosophical Transactions of the Royal Society B: Biological Sciences, 363(1512), 4023-4029. doi: $10.1098 /$ rstb.2008.0144

Garrison, E. (2012). Vcflib: A C++ library for parsing and manipulating VCF files. Github. https://github. com/ekg/vcflib.

Garrison, E., \& Marth, G. (2012). Haplotype-based variant detection from short-read sequencing. arXiv:1207.3907 [q-bio].

Gavrilets, S., \& Losos, J. B. (2009). Adaptive Radiation: Contrasting Theory with Data. Science, 323(5915), 732-737. doi: 10.1126/science.1157966

Givnish, T. J., Barfuss, M. H. J., Ee, B. V., Riina, R., Schulte, K., Horres, R., ... Sytsma, K. J. (2011). Phylogeny, adaptive radiation, and historical biogeography in Bromeliaceae: Insights from an eight-locus plastid phylogeny. American Journal of Botany, 98(5), 872-895. doi: 10.3732 /ajb.1000059

Givnish, T. J., Barfuss, M. H. J., Ee, B. V., Riina, R., Schulte, K., Horres, R., ... Sytsma, K. J. (2014). Adaptive radiation, correlated and contingent evolution, and net species diversification in Bromeliaceae. Molecular Phylogenetics and Evolution, 71, 55-78. doi: 10.1016/j.ympev.2013.10.010

Givnish, T. J., Burkhardt, E. L., Happel, R. E., \& Weintraub, J. D. (1984). Carnivory in the Bromeliad Brocchinia reducta, with a Cost/Benefit Model for the General Restriction of Carnivorous Plants to Sunny, Moist, Nutrient-Poor Habitats. The American Naturalist, 124(4), 479-497. doi: 10.1086/284289

Goetze, M., Zanella, C. M., Palma-Silva, C., Büttow, M. V., \& Bered, F. (2017). Incomplete lineage sorting and hybridization in the evolutionary history of closely related, endemic yellow-flowered Aechmea species of subgenus Ortgiesia (Bromeliaceae). American Journal of Botany, 104(7), 1073-1087. doi: 10.3732/ajb.1700103 
Taxon-specific or universal?

Goolsby, E. W., Moore, A. J., Hancock, L. P., Vos, J. M. D., \& Edwards, E. J. (2018). Molecular evolution of key metabolic genes during transitions to C4 and CAM photosynthesis. American Journal of Botany, 105(3), 602-613. doi: 10.1002/ajb2.1051

Granados Mendoza, C., Granados-Aguilar, X., Donadío, S., Salazar, G. A., Flores-Cruz, M., Hágsater, E., ... Magallón, S. (2017). Geographic structure in two highly diverse lineages of Tillandsia (Bromeliaceae). Botany, 95(7), 641-651. doi: 10.1139/cjb-2016-0250

Hale, H., Gardner, E. M., Viruel, J., Pokorny, L., \& Johnson, M. G. (2020). Strategies for reducing per-sample costs in target capture sequencing for phylogenomics and population genomics in plants. Applications in Plant Sciences, 8(4), e11337. doi: 10.1002/aps3.11337

Heckenhauer, J., Samuel, R., Ashton, P. S., Abu Salim, K., \& Paun, O. (2018). Phylogenomics resolves evolutionary relationships and provides insights into floral evolution in the tribe Shoreeae (Dipterocarpaceae). Molecular Phylogenetics and Evolution, 127, 1-13. doi: 10.1016/j.ympev.2018.05.010

Hedin, M., Derkarabetian, S., Ramírez, M. J., Vink, C., \& Bond, J. E. (2018). Phylogenomic reclassification of the world's most venomous spiders (Mygalomorphae, Atracinae), with implications for venom evolution. Scientific Reports, 8(1), 1636. doi: 10.1038/s41598-018 $-19946-2$

Heyduk, K., Moreno-Villena, J. J., Gilman, I. S., Christin, P.-A., \& Edwards, E. J. (2019). The genetics of convergent evolution: Insights from plant photosynthesis. Nature Reviews Genetics, 20(8), 485-493. doi: 10.1038/s41576-019-0107-5

Hime, P. M., Lemmon, A. R., Lemmon, E. C. M., Prendini, E., Brown, J. M., Thomson, R. C., ... Weisrock, D. W. (2021). Phylogenomics Reveals Ancient Gene Tree Discordance in the Amphibian Tree of Life. Systematic Biology, 70(1), 49-66. doi: 10.1093/sysbio/syaa034

Hollingsworth, P. M., Li, D.-Z., van der Bank, M., \& Twyford, A. D. (2016). Telling plant species apart with DNA: From barcodes to genomes. Philosophical Transactions of the Royal Society B: Biological Sciences, 371(1702), 20150338. doi: 10.1098/rstb.2015.0338

Hudlow, W. R., Krieger, R., Meusel, M., Sehhat, J. C., Timken, M. D., \& Buoncristiani, M. R. (2011). The NucleoSpin® DNA Clean-up XS kit for the concentration and purification of genomic DNA extracts: An alternative to microdialysis filtration. Forensic Science International. Genetics, 5(3), 226-230. doi: 10.1016/j.fsigen.2010.03.005

Hughes, C. E., Nyffeler, R., \& Linder, H. P. (2015). Evolutionary plant radiations: Where, when, why and how? New Phytologist, 207(2), 249-253. doi: 10.1111/nph.13523

Johnson, M. G., Pokorny, L., Dodsworth, S., Botigué, L. R., Cowan, R. S., Devault, A., ... Wickett, N. J. (2019). A Universal Probe Set for Targeted Sequencing of 353 Nuclear Genes from Any Flowering Plant Designed Using k-Medoids Clustering. Systematic Biology, 68(4), 594-606. doi: 10.1093/sysbio/syy086 
Taxon-specific or universal?

Jones, M. R., \& Good, J. M. (2016). Targeted capture in evolutionary and ecological genomics. Molecular Ecology, 25(1), 185-202. doi: 10.1111/mec.13304

Junier, T., \& Zdobnov, E. M. (2010). The Newick utilities: High-throughput phylogenetic tree processing in the UNIX shell. Bioinformatics (Oxford, England), 26(13), 1669-1670. doi: 10.1093/bioinformatics/btq243

Kadlec, M., Bellstedt, D. U., Maitre, N. C. L., \& Pirie, M. D. (2017). Targeted NGS for species level phylogenomics: "made to measure" or "one size fits all"? PeerJ, 5, e3569. doi: $10.7717 /$ peerj.3569

Kessler, M., Abrahamczyk, S., \& Krömer, T. (2020). The role of hummingbirds in the evolution and diversification of Bromeliaceae: Unsupported claims and untested hypotheses. Botanical Journal of the Linnean Society, 192(4), 592-608. doi: 10.1093/botlinnean/ boz100

Kozlov, A. M., Darriba, D., Flouri, T., Morel, B., \& Stamatakis, A. (2019). RAxMLNG: A fast, scalable and user-friendly tool for maximum likelihood phylogenetic inference. Bioinformatics, 35(21), 4453-4455. doi: 10.1093/bioinformatics/btz305

Krueger, F. (2019). Trim Galore: A wrapper tool around Cutadapt and FastQC to consistently apply quality and adapter trimming to FastQ files, with some extra functionality for MspI-digested RRBS-type (Reduced Representation Bisufite-Seq) libraries. Babraham Bioinformatics, Babraham Institute, Cambridge, United Kingdom.

Kubatko, L. S., \& Degnan, J. H. (2007). Inconsistency of Phylogenetic Estimates from Concatenated Data under Coalescence. Systematic Biology, 56(1), 17-24. doi: 10.1080/ 10635150601146041

Lamichhaney, S., Berglund, J., Almén, M. S., Maqbool, K., Grabherr, M., Martinez-Barrio, A., ... Andersson, L. (2015). Evolution of Darwin's finches and their beaks revealed by genome sequencing. Nature, 518(7539), 371-375. doi: 10.1038/nature14181

Langmead, B., \& Salzberg, S. L. (2012). Fast gapped-read alignment with Bowtie 2. Nature Methods, 9(4), 357-359. doi: 10.1038/nmeth.1923

Larridon, I., Villaverde, T., Zuntini, A. R., Pokorny, L., Brewer, G. E., Epitawalage, N., ... Baker, W. J. (2020). Tackling Rapid Radiations With Targeted Sequencing. Frontiers in Plant Science, 10. doi: 10.3389/fpls.2019.01655

Lemmon, A. R., Brown, J. M., Stanger-Hall, K., \& Lemmon, E. M. (2009). The Effect of Ambiguous Data on Phylogenetic Estimates Obtained by Maximum Likelihood and Bayesian Inference. Systematic Biology, 58(1), 130-145. doi: 10.1093/sysbio/syp017

Lemmon, A. R., Emme, S. A., \& Lemmon, E. M. (2012). Anchored Hybrid Enrichment for Massively High-Throughput Phylogenomics. Systematic Biology, 61(5), 727-744. doi: 10.1093/sysbio/sys049 
Taxon-specific or universal?

Lemmon, E. M., \& Lemmon, A. R. (2013). High-Throughput Genomic Data in Systematics and Phylogenetics. Annual Review of Ecology, Evolution, and Systematics, 44(1), 99-121. doi: 10.1146/annurev-ecolsys-110512-135822

Leroy, C., Carrias, J.-F., Céréghino, R., \& Corbara, B. (2016). The contribution of microorganisms and metazoans to mineral nutrition in bromeliads. Journal of Plant Ecology, 9(3), 241-255. doi: 10.1093/jpe/rtv052

Leroy, T., Rousselle, M., Tilak, M.-K., Caizergues, A. E., Scornavacca, C., Recuerda, M., ... Nabholz, B. (2021). Island songbirds as windows into evolution in small populations. Current Biology. doi: 10.1016/j.cub.2020.12.040

Li, H. (2011). A statistical framework for SNP calling, mutation discovery, association mapping and population genetical parameter estimation from sequencing data. Bioinformatics, 27(21), 2987-2993. doi: 10.1093/bioinformatics/btr509

Li, H., Handsaker, B., Wysoker, A., Fennell, T., Ruan, J., Homer, N., ... Durbin, R. (2009). The Sequence Alignment/Map format and SAMtools. Bioinformatics, 25(16), 2078-2079. doi: 10.1093/bioinformatics/btp352

Linder, H. P. (2008). Plant species radiations: Where, when, why? Philosophical Transactions of the Royal Society B: Biological Sciences, 363(1506), 3097-3105. doi: $10.1098 /$ rstb.2008.0075

Liu, Y., Johnson, M. G., Cox, C. J., Medina, R., Devos, N., Vanderpoorten, A., ... Goffinet, B. (2019). Resolution of the ordinal phylogeny of mosses using targeted exons from organellar and nuclear genomes. Nature Communications, 10(1), 1485. doi: 10.1038/ s41467-019-09454-w

Loiseau, O., Machado, T. M., Paris, M., Koubínová, D., Dexter, K., Versieux, L., ... Salamin, N. (2021). Genome skimming reveals widespread hybridization in a Neotropical flowering plant radiation. Frontiers in Ecology and Evolution, 9. doi: 10.3389/fevo.2021.668281

Luther, H. E. (2008). An alphabetical list of bromeliad binomials (Eleventh ed.). The Marie Selby Botanical Gardens Sarasota, Florida, USA: the Bromeliad Society International.

Machado, T. M., Loiseau, O., Paris, M., Weigand, A., Versieux, L. M., Stehmann, J. R., ... Salamin, N. (2020). Systematics of Vriesea (Bromeliaceae): Phylogenetic relationships based on nuclear gene and partial plastome sequences. Botanical Journal of the Linnean Society, 192(4), 656-674. doi: 10.1093/botlinnean/boz102

Madden, T. L. (2013). The BLAST sequence analysis tool. In The NCBI Handbook [Internet] (Second ed.). US: National Center for Biotechnology Information.

McDonnell, A. J., Baker, W. J., Dodsworth, S., Forest, F., Graham, S. W., Johnson, M. G., ... Wickett, N. J. (2021). Exploring Angiosperms353: Developing and applying a universal toolkit for flowering plant phylogenomics. Applications in Plant Sciences, 9(7), 10.1002/aps3.11443. doi: 10.1002/aps3.11443 
Taxon-specific or universal?

McGee, M. D., Borstein, S. R., Meier, J. I., Marques, D. A., Mwaiko, S., Taabu, A., ... Seehausen, O. (2020). The ecological and genomic basis of explosive adaptive radiation. Nature, 1-5. doi: 10.1038/s41586-020-2652-7

McGlothlin, J. W., Kobiela, M. E., Wright, H. V., Mahler, D. L., Kolbe, J. J., Losos, J. B., \& Brodie, E. D. (2018). Adaptive radiation along a deeply conserved genetic line of least resistance in Anolis lizards. Evolution Letters, 2(4), 310-322. doi: 10.1002/evl3.72

McGowen, M. R., Tsagkogeorga, G., Álvarez-Carretero, S., dos Reis, M., Struebig, M., Deaville, R., ... Rossiter, S. J. (2020). Phylogenomic Resolution of the Cetacean Tree of Life Using Target Sequence Capture. Systematic Biology, 69(3), 479-501. doi: $10.1093 /$ sysbio/syz068

McKain, M. R., Johnson, M. G., Uribe-Convers, S., Eaton, D., \& Yang, Y. (2018). Practical considerations for plant phylogenomics. Applications in Plant Sciences, 6(3), e1038. doi: 10.1002/aps3.1038

Ming, R., VanBuren, R., Wai, C. M., Tang, H., Schatz, M. C., Bowers, J. E., ... Yu, Q. (2015). The pineapple genome and the evolution of CAM photosynthesis. Nature Genetics, 47(12), 1435-1442. doi: 10.1038/ng.3435

Mirarab, S. (2019). Species Tree Estimation Using ASTRAL: Practical Considerations. arXiv:1904.03826 [q-bio].

Moest, M., Belleghem, S. M. V., James, J. E., Salazar, C., Martin, S. H., Barker, S. L., ... Jiggins, C. D. (2020). Selective sweeps on novel and introgressed variation shape mimicry loci in a butterfly adaptive radiation. PLOS Biology, 18(2), e3000597. doi: 10.1371/journal.pbio.3000597

Molloy, E. K., \& Warnow, T. (2018). To Include or Not to Include: The Impact of Gene Filtering on Species Tree Estimation Methods. Systematic Biology, 67(2), 285-303. doi: 10.1093/sysbio/syx077

Morales-Briones, D. F., Gehrke, B., Huang, C.-H., Liston, A., Ma, H., Marx, H. E., ... Yang, Y. (2020). Analysis of paralogs in target enrichment data pinpoints multiple ancient polyploidy events in Alchemilla s.l. (Rosaceae). bioRxiv, 2020.08.21.261925. doi: 10.1101/ 2020.08.21.261925

Morel, B., Kozlov, A. M., \& Stamatakis, A. (2019). ParGenes: A tool for massively parallel model selection and phylogenetic tree inference on thousands of genes. Bioinformatics, 35(10), 1771-1773. doi: 10.1093/bioinformatics/bty839

Mota, M. R., Pinheiro, F., Leal, B. S. d. S., Sardelli, C. H., Wendt, T., \& Palma-Silva, C. (2020). From micro- to macroevolution: Insights from a Neotropical bromeliad with high population genetic structure adapted to rock outcrops. Heredity, 1-18. doi: 10.1038/ s41437-020-0342-8 
Taxon-specific or universal?

Moyle, R. G., Filardi, C. E., Smith, C. E., \& Diamond, J. (2009). Explosive Pleistocene diversification and hemispheric expansion of a "great speciator". Proceedings of the National Academy of Sciences, 106(6), 1863-1868. doi: 10.1073/pnas.0809861105

Murphy, B., Forest, F., Barraclough, T., Rosindell, J., Bellot, S., Cowan, R., ... Cheek, M. (2020). A phylogenomic analysis of Nepenthes (Nepenthaceae). Molecular Phylogenetics and Evolution, 144, 106668. doi: 10.1016/j.ympev.2019.106668

Nevado, B., Atchison, G. W., Hughes, C. E., \& Filatov, D. A. (2016). Widespread adaptive evolution during repeated evolutionary radiations in New World lupins. Nature Communications, 7(1), 12384. doi: 10.1038/ncomms12384

Nute, M., Chou, J., Molloy, E. K., \& Warnow, T. (2018). The performance of coalescentbased species tree estimation methods under models of missing data. BMC Genomics, 19(5), 286. doi: 10.1186/s12864-018-4619-8

Ogutcen, E., Christe, C., Nishii, K., Salamin, N., Möller, M., \& Perret, M. (2021). Phylogenomics of Gesneriaceae using targeted capture of nuclear genes. Molecular Phylogenetics and Evolution, 107068. doi: 10.1016/j.ympev.2021.107068

Ortiz, E. M. (2019). Vcf2phylip v2.0: Convert a VCF matrix into several matrix formats for phylogenetic analysis. Zenodo. doi: 10.5281/zenodo.2540861

Palma-Silva, C., \& Fay, M. F. (2020). Bromeliaceae as a model group in understanding the evolution of Neotropical biota. Botanical Journal of the Linnean Society, 192(4), 569-586. doi: 10.1093/botlinnean/boaa003

Palma-Silva, C., Ferro, M., Bacci, M., \& Turchetto-Zolet, A. C. (2016). De novo assembly and characterization of leaf and floral transcriptomes of the hybridizing bromeliad species (Pitcairnia spp.) adapted to Neotropical Inselbergs. Molecular Ecology Resources, 16(4), 1012-1022. doi: 10.1111/1755-0998.12504

Pease, J. B., Haak, D. C., Hahn, M. W., \& Moyle, L. C. (2016). Phylogenomics Reveals Three Sources of Adaptive Variation during a Rapid Radiation. PLOS Biology, 14(2), e1002379. doi: 10.1371/journal.pbio.1002379

Pfeifer, B., Wittelsbürger, U., Ramos-Onsins, S. E., \& Lercher, M. J. (2014). PopGenome: An Efficient Swiss Army Knife for Population Genomic Analyses in R. Molecular Biology and Evolution, 31(7), 1929-1936. doi: 10.1093/molbev/msu136

Picard toolkit. (2019). Broad Institute, GitHub repository. http://broadinstitute.github.io/picard/.

Quattrini, A. M., Faircloth, B. C., Dueñas, L. F., Bridge, T. C. L., Brugler, M. R., CalixtoBotía, I. F., ... McFadden, C. S. (2018). Universal target-enrichment baits for anthozoan (Cnidaria) phylogenomics: New approaches to long-standing problems. Molecular Ecology Resources, 18(2), 281-295. doi: 10.1111/1755-0998.12736 
Taxon-specific or universal?

Quezada, I. M., \& Gianoli, E. (2011). Crassulacean acid metabolism photosynthesis in Bromeliaceae: An evolutionary key innovation. Biological Journal of the Linnean Society, 104(2), 480-486. doi: 10.1111/j.1095-8312.2011.01713.x

Quinlan, A. R., \& Hall, I. M. (2010). BEDTools: A flexible suite of utilities for comparing genomic features. Bioinformatics, 26(6), 841-842. doi: 10.1093/bioinformatics/btq033

R Core Team. (2020). R: A language and environment for statistical computing. R Foundation for Statistical Computing. Vienna, Austria.

Renaud, G., Stenzel, U., Maricic, T., Wiebe, V., \& Kelso, J. (2015). deML: Robust demultiplexing of Illumina sequences using a likelihood-based approach. Bioinformatics (Oxford, England), 31(5), 770-772. doi: 10.1093/bioinformatics/btu719

Roch, S., \& Warnow, T. (2015). On the Robustness to Gene Tree Estimation Error (or lack thereof) of Coalescent-Based Species Tree Methods. Systematic Biology, 64(4), 663-676. doi: $10.1093 /$ sysbio/syv016

Salzburger, W. (2018). Understanding explosive diversification through cichlid fish genomics. Nature Reviews Genetics, 19(11), 705-717. doi: 10.1038/s41576-018-0043-9

Sanderson, B. J., DiFazio, S. P., Cronk, Q. C. B., Ma, T., \& Olson, M. S. (2020). A targeted sequence capture array for phylogenetics and population genomics in the Salicaceae. Applications in Plant Sciences, 8(10), e11394. doi: 10.1002/aps3.11394

Sass, C., Iles, W. J. D., Barrett, C. F., Smith, S. Y., \& Specht, C. D. (2016). Revisiting the Zingiberales: Using multiplexed exon capture to resolve ancient and recent phylogenetic splits in a charismatic plant lineage. PeerJ, 4, e1584. doi: 10.7717/peerj.1584

Sayyari, E., \& Mirarab, S. (2016). Fast Coalescent-Based Computation of Local Branch Support from Quartet Frequencies. Molecular Biology and Evolution, 33(7), 1654-1668. doi: 10.1093/molbev/msw079

Schulte, K., Barfuss, M. H. J., \& Zizka, G. (2009). Phylogeny of Bromelioideae (Bromeliaceae) inferred from nuclear and plastid DNA loci reveals the evolution of the tank habit within the subfamily. Molecular Phylogenetics and Evolution, 51(2), 327-339. doi: 10.1016/j.ympev.2009.02.003

Shah, T., Schneider, J. V., Zizka, G., Maurin, O., Baker, W., Forest, F., ... Larridon, I. (2021). Joining forces in Ochnaceae phylogenomics: A tale of two targeted sequencing probe kits. American Journal of Botany, 108(7), 1201-1216. doi: 10.1002/ajb2.1682

Shee, Z. Q., Frodin, D. G., Cámara-Leret, R., \& Pokorny, L. (2020). Reconstructing the Complex Evolutionary History of the Papuasian Schefflera Radiation Through Herbariomics. Frontiers in Plant Science, 11. doi: 10.3389/fpls.2020.00258 
Taxon-specific or universal?

Silvera, K., Neubig, K. M., Whitten, W. M., Williams, N. H., Winter, K., \& Cushman, J. C. (2010). Evolution along the crassulacean acid metabolism continuum. Functional Plant Biology, 37(11), 995-1010. doi: 10.1071/FP10084

Slimp, M., Williams, L. D., Hale, H., \& Johnson, M. G. (2021). On the potential of Angiosperms353 for population genomics. Applications in Plant Sciences, 9((7): e11419). doi: doi:10.1002/aps3.11419

Soltis, P. S., Folk, R. A., \& Soltis, D. E. (2019). Darwin review: Angiosperm phylogeny and evolutionary radiations. Proceedings of the Royal Society B: Biological Sciences, 286(1899), 20190099. doi: 10.1098/rspb.2019.0099

Soltis, P. S., \& Soltis, D. E. (2004). The origin and diversification of angiosperms. American Journal of Botany, 91(10), 1614-1626. doi: 10.3732/ajb.91.10.1614

Soto-Gomez, M. S., Pokorny, L., Kantar, M. B., Forest, F., Leitch, I. J., Gravendeel, B., ... Viruel, J. (2019). A customized nuclear target enrichment approach for developing a phylogenomic baseline for Dioscorea yams (Dioscoreaceae). Applications in Plant Sciences, 7(6), e11254. doi: 10.1002/aps3.11254

Straub, S. C. K., Moore, M. J., Soltis, P. S., Soltis, D. E., Liston, A., \& Livshultz, T. (2014). Phylogenetic signal detection from an ancient rapid radiation: Effects of noise reduction, long-branch attraction, and model selection in crown clade Apocynaceae. Molecular Phylogenetics and Evolution, 80, 169-185. doi: 10.1016/j.ympev.2014.07.020

Straub, S. C. K., Parks, M., Weitemier, K., Fishbein, M., Cronn, R. C., \& Liston, A. (2012). Navigating the tip of the genomic iceberg: Next-generation sequencing for plant systematics. American Journal of Botany, 99(2), 349-364. doi: 10.3732/ajb.1100335

Streicher, J. W., Schulte, J. A., \& Wiens, J. J. (2016). How Should Genes and Taxa be Sampled for Phylogenomic Analyses with Missing Data? An Empirical Study in Iguanian Lizards. Systematic Biology, 65(1), 128-145. doi: 10.1093/sysbio/syv058

Stroud, J. T., \& Losos, J. B. (2020). Bridging the Process-Pattern Divide to Understand the Origins and Early Stages of Adaptive Radiation: A Review of Approaches With Insights From Studies of Anolis Lizards. Journal of Heredity, 111(1), 33-42. doi: 10.1093/jhered/ esz055

Supple, M. A., \& Shapiro, B. (2018). Conservation of biodiversity in the genomics era. Genome Biology, 19(1), 131. doi: 10.1186/s13059-018-1520-3

Thomas, A. E., Igea, J., Meudt, H. M., Albach, D. C., Lee, W. G., \& Tanentzap, A. J. (2021). Using target sequence capture to improve the phylogenetic resolution of a rapid radiation in New Zealand Veronica. American Journal of Botany, 108(7), 1289-1306. doi: 10.1002/ajb2.1678 
Taxon-specific or universal?

Ufimov, R., Zeisek, V., Píšová, S., Baker, W. J., Fér, T., van Loo, M., ... Schmickl, R. (2021). Relative performance of customized and universal probe sets in target enrichment: A case study in subtribe Malinae. Applications in Plant Sciences, 9(7), e11442. doi: 10.1002/aps3.11442

Van de Peer, Y., Mizrachi, E., \& Marchal, K. (2017). The evolutionary significance of polyploidy. Nature Reviews Genetics, 18(7), 411-424. doi: 10.1038/nrg.2017.26

Versieux, L. M., Barbará, T., Wanderley, M. d. G. L., Calvente, A., Fay, M. F., \& Lexer, C. (2012). Molecular phylogenetics of the Brazilian giant bromeliads (Alcantarea, Bromeliaceae): Implications for morphological evolution and biogeography. Molecular Phylogenetics and Evolution, 64(1), 177-189. doi: 10.1016/j.ympev.2012.03.015

Villaverde, T., Pokorny, L., Olsson, S., Rincón-Barrado, M., Johnson, M. G., Gardner, E. M., ... Sanmartín, I. (2018). Bridging the micro- and macroevolutionary levels in phylogenomics: Hyb-Seq solves relationships from populations to species and above. New Phytologist, 220(2), 636-650. doi: 10.1111/nph.15312

Viruel, J., Conejero, M., Hidalgo, O., Pokorny, L., Powell, R. F., Forest, F., ... Leitch, I. J. (2019). A Target Capture-Based Method to Estimate Ploidy From Herbarium Specimens. Frontiers in Plant Science, 10. doi: 10.3389/fpls.2019.00937

Wai, C. M., VanBuren, R., Zhang, J., Huang, L., Miao, W., Edger, P. P., ... Ming, R. (2017). Temporal and spatial transcriptomic and microRNA dynamics of CAM photosynthesis in pineapple. The Plant Journal, 92(1), 19-30. doi: 10.1111/tpj.13630

Weitemier, K., Straub, S. C. K., Cronn, R. C., Fishbein, M., Schmickl, R., McDonnell, A., \& Liston, A. (2014). Hyb-Seq: Combining target enrichment and genome skimming for plant phylogenomics. Applications in Plant Sciences, 2(9), 1400042. doi: 10.3732/apps.1400042

Wendel, J. F., \& Doyle, J. J. (1998). Phylogenetic Incongruence: Window into Genome History and Molecular Evolution. In D. E. Soltis, P. S. Soltis, \& J. J. Doyle (Eds.), Molecular Systematics of Plants II: DNA Sequencing (pp. 265-296). Boston, MA: Springer US. doi: 10.1007/978-1-4615-5419-6_10

Wöhrmann, T., Michalak, I., Zizka, G., \& Weising, K. (2020). Strong genetic differentiation among populations of Fosterella rusbyi (Bromeliaceae) in Bolivia. Botanical Journal of the Linnean Society, 192(4), 744-759. doi: 10.1093/botlinnean/boz096

Xi, Z., Liu, L., \& Davis, C. C. (2016). The Impact of Missing Data on Species Tree Estimation. Molecular Biology and Evolution, 33(3), 838-860. doi: 10.1093/molbev/msv266

Zhang, C., Rabiee, M., Sayyari, E., \& Mirarab, S. (2018). ASTRAL-III: Polynomial time species tree reconstruction from partially resolved gene trees. BMC Bioinformatics, 19(6), 153. doi: 10.1186/s12859-018-2129-y 
Taxon-specific or universal?

1050

1051

1052

1053

1054

1055

1056

1057

1058
Zheng, X., Levine, D., Shen, J., Gogarten, S. M., Laurie, C., \& Weir, B. S. (2012). A high-performance computing toolset for relatedness and principal component analysis of SNP data. Bioinformatics, 28(24), 3326-3328. doi: 10.1093/bioinformatics/bts606

Zimmer, E. A., \& Wen, J. (2013). Reprint of: Using nuclear gene data for plant phylogenetics: Progress and prospects. Molecular Phylogenetics and Evolution, 66(2), 539-550. doi: 10.1016/j.ympev.2013.01.005

Zink, R. M., \& Vázquez-Miranda, H. (2019). Species Limits and Phylogenomic Relationships of Darwin's Finches Remain Unresolved: Potential Consequences of a Volatile Ecological Setting. Systematic Biology, 68(2), 347-357. doi: 10.1093/sysbio/syy073 
Taxon-specific or universal?

1059

1060

1061

1062

1063

1064

1065

1066

1067

1068

1069

1070

\section{Data Accessibility}

Targeted sequencing reads generated for this project are available at NCBI-SRA under BioProject PRJNA759878; for accession numbers, see supporting information Table S4. The probe set and the relevant supporting information are available in Dryad (doi:10.5061/dryad.mpg4f4r11). The bioinformatics scripts are available at https://github.com/giyany/Bromeliad1776/tree/main/ MS_2021_scripts.

\section{Author Contribution}

CL, MP and GY conceived the study. CL provided funding. TK coordinated sample collection, MdLH, VGJ and GY collected data. Species identified by MHJB and WT. Bait kit designed by GY, with guidance from JH and MP. Molecular work was performed by CGC, JV, NR, MHJB and GY. The data was analyzed by GY and TL with feedback from JV and OP. The manuscript was written by GY with significant input from all co-authors. 
bioRxiv preprint doi: https://doi.org/10.1101/2021.05.20.444989; this version posted September 20, 2021. The copyright holder for this preprint (which was not certified by peer review) is the author/funder, who has granted bioRxiv a license to display the preprint in perpetuity. It is made available under aCC-BY-NC 4.0 International license.

Taxon-specific or universal?

${ }_{1071} 9$ Tables

1072 Table 1 Number and characteristics of the variants obtained for Angiosperms353 and Bromeliad1776. 1073 
bioRxiv preprint doi: https://doi.org/10.1101/2021.05.20.444989; this version posted September 20, 2021. The copyright holder for this preprint

(which was not certified by peer review) is the author/funder, who has granted bioRxiv a license to display the preprint in perpetuity. It is made available under aCC-BY-NC 4.0 International license.

Taxon-specific or universal?

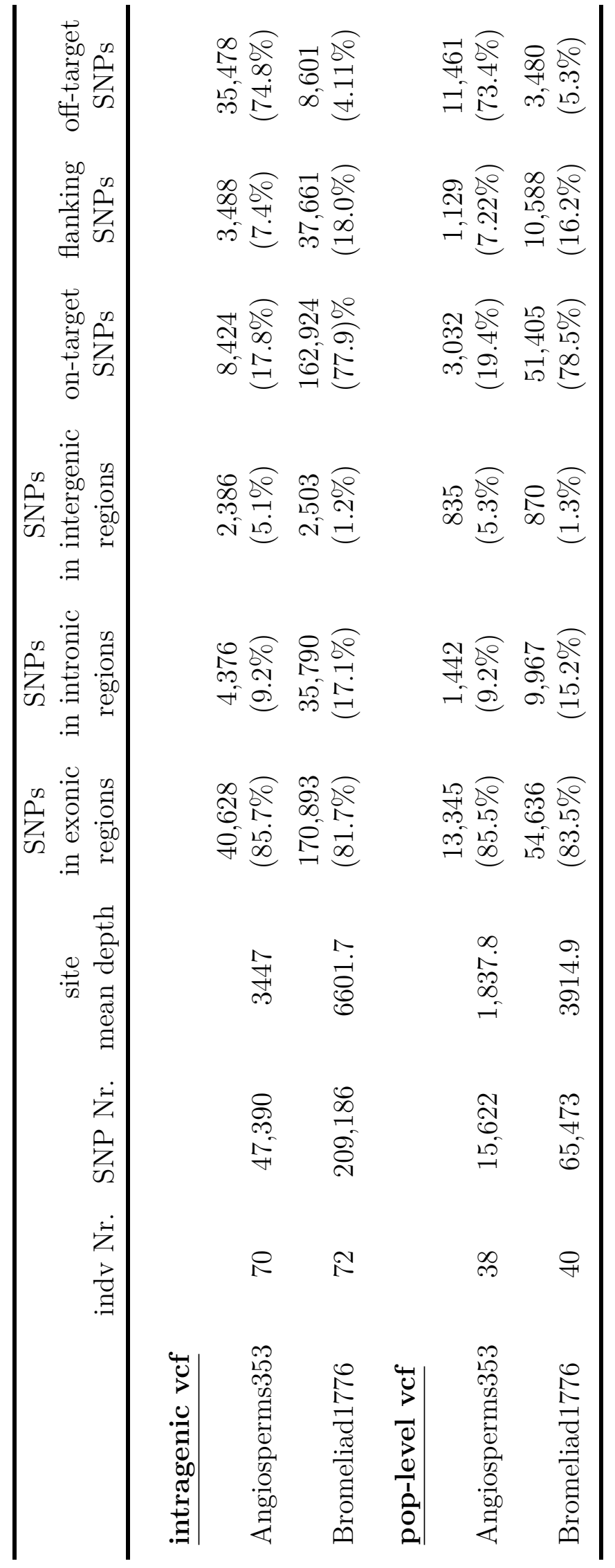


Taxon-specific or universal?

\section{Supporting information}

\subsection{Tables}

Table S1 Genes included in the Bromeliad1776 bait design, with identifiers as annotated in Ananas comosus genome v.3 (Ming et al., 2015). The table includes details about exon composition, copy number and putatively associated pathways.

Table S2 Categories of pathways and traits used to choose genes of interest for the Bromeliad1776 bait set, including literature source and number of genes in each category.

Table S3 List of accessions used in this study. For samples of Tillandsia subgenus Tillandsia locality codes are also indicated.

Table S4 Number of reads, numbers and percentage of read mapping to target in all samples for both bait sets.

Table S5 Averaged levels of nucleotide diversity at synonymous $\left(\pi_{\mathrm{S}}\right)$ and non-synonymous $\left(\pi_{\mathrm{N}}\right)$ for 5 Tillandsia subgenus Tillandsia species.

\section{$10.2 \quad$ Figures}

Figure S1 Map of sampling locations for Tillandsia subgenus Tillandsia accessions within Mexico.

Figure S2 Mapping rates (A) and percentage of reads matching bait sequences (B) for Bromeliad samples enriched with one of two bait sets: Angiosperms353 and Bromeliad1776. Reads were mapped against $A$. comosus reference for both bait sets. Targets were defined as bait locations and flanking 500 base-pairs. Bromeliad1776 targets were defined as the regions used for bait design and Angiosperms353 targets were defined as A. comosus orthologous regions matching the genes used for bait design.

Figure S3 A simplified phylogenetic tree, with branches colored according to read mapping percentage for samples enriched with Angiosperms353.

Figure S4 A simplified phylogenetic tree, with branches colored according to read mapping percentage for samples enriched with Bromeliad1776.

Figure S5 Maximum-likelihood (ML) phylogenetic tree inferred with RAxML-NG, based on variants called for data sets enriched with Bromeliad1776 bait set (left) and Angiosperms353 bait set (right, flipped for mirroring). Branch lengths were calculated by number of substitutions per site. Internal nodes are marked and colored according to bootstrap support. Nodes which differed among trees are colored purple and have been marked by an arrow. 
Taxon-specific or universal?

1105

1106

1107

1108

1109

1110

1111

1112

1113

1114

1115

1116

1117

1118

Figure S6 Principal Component Analysis (PCA) plot for samples of Tillandsia subgenus Tillandsia enriched with two bait sets: A. Angiosperms353 (1,025 variants after LD-pruning) B. Bromeliad1776 (32,941 variants after LD-pruning). Colors indicate different species (following the scheme in Supporting Figure S6) and shapes represent different geographic origins (populations).

Figure S7 Admixture cross-validation errors (top) detected for values of $\mathrm{K}$ between 2 and 9 for A. Angiosperms353 data set and B. Bromeliad1776 data set.

Figure S8 Coalescent-based species trees generated ASTRAL-III for samples enriched with Angiosperms353 using 269 genes. Node values represent local posterior probabilities (pp) for the main topology.

Figure S9 Coalescent-based species trees generated ASTRAL-III for samples enriched with Bromeliad1776 using 1600 genes. Node values represent local posterior probabilities (pp) for the main topology.

\subsection{Files}

File S1 Estimation of ascertainment bias in target capture data using comparison with wholegenome data 

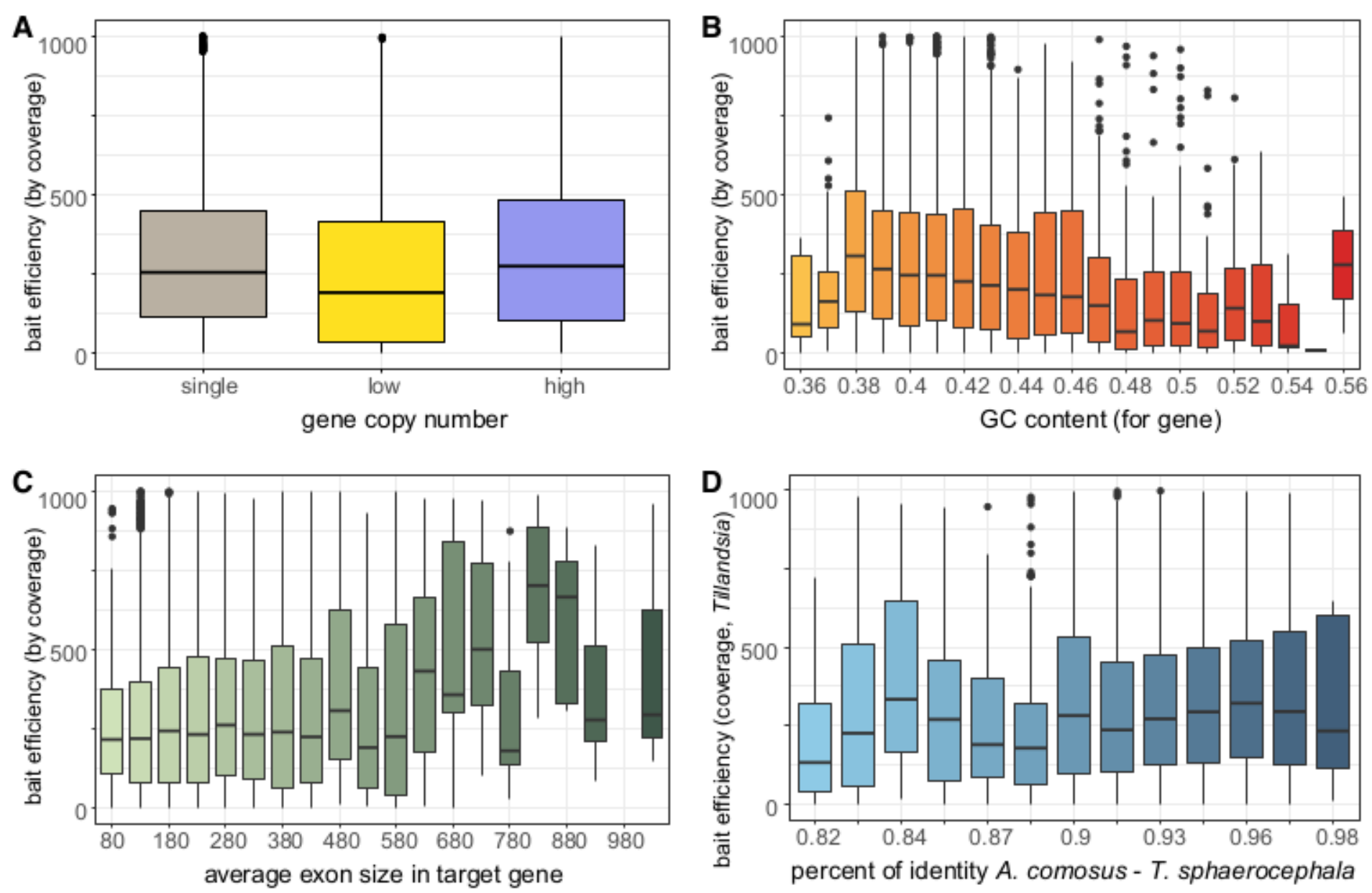

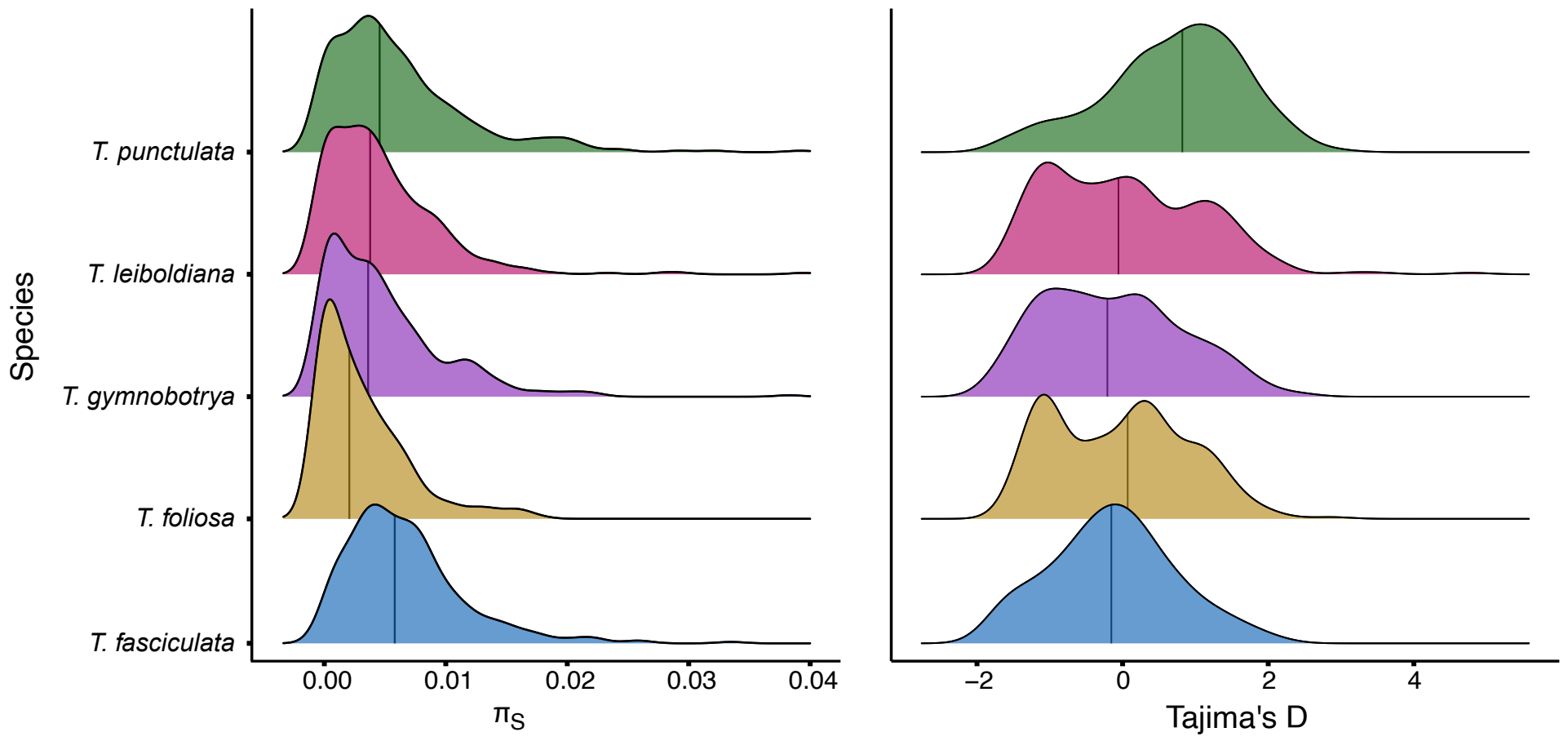